\title{
THREE-DIMENSIONAL THERMAL MODELING ANALYSIS OF CST MEDIA FOR THE SMALL COLUMN ION EXCHANGE PROJECT
}

\section{SEPTEMBER 2011}

Savannah River National Laboratory Savannah River Nuclear Solutions, LLC Aiken, SC 29808

Prepared for the U.S. Department of Energy under contract number DE-AC09-08SR22470.

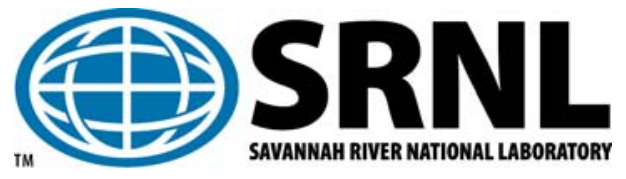




\section{DISCLAIMER}

This work was prepared under an agreement with and funded by the U.S. Government. Neither the U.S. Government or its employees, nor any of its contractors, subcontractors or their employees, makes any express or implied:

1. warranty or assumes any legal liability for the accuracy, completeness, or for the use or results of such use of any information, product, or process disclosed; or

2. representation that such use or results of such use would not infringe privately owned rights; or

3. endorsement or recommendation of any specifically identified commercial product, process, or service.

Any views and opinions of authors expressed in this work do not necessarily state or reflect those of the United States Government, or its contractors, or subcontractors.

\section{Printed in the United States of America}

Prepared for

U.S. Department of Energy 
Key Words:

Thermal Modeling Heat

Transfer Analysis Crystalline

Silicotitanate IX Column

High Level Waste Tank

Retention:

Permanent

\title{
THREE-DIMENSIONAL THERMAL MODELING ANALYSIS OF CST MEDIA FOR THE SMALL COLUMN ION EXCHANGE PROJECT
}

\author{
Si Young Lee \\ William D. King
}

\section{SEPTEMBER 2011}

Savannah River National Laboratory

Savannah River Nuclear Solutions, LLC Aiken, SC 29808

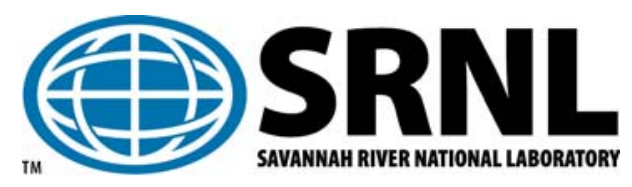




\section{REVIEWS AND APPROVALS}

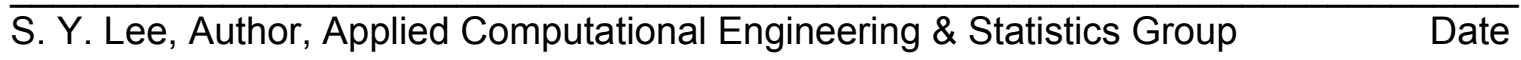

W. D. King, Coauthor, Adv. Characterization \& Process Group Date

$\overline{\text { F. G. Smith, III, Reviewer, Process Modeling \& Computational Chemistry Group Date }}$

$\overline{\text { P. L. Lee, Manager, Applied Computational Engineering \& Statistics Group Date }}$

S. J. Hensel, Manager, Computational Engineering \& Sciences Section Date

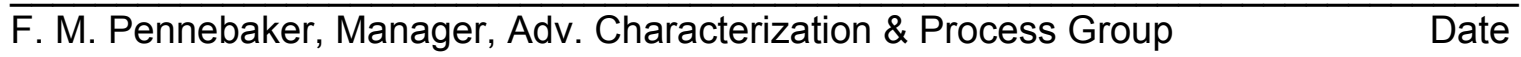

T. H. Huff, Customer, SRR Engineering $\quad$ Date 


\section{TABLE OF CONTENTS}

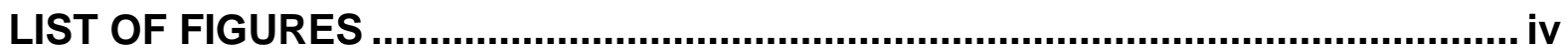

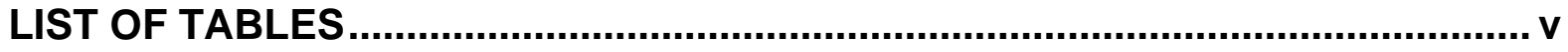

LIST OF ACRONYMS .................................................................................. vi

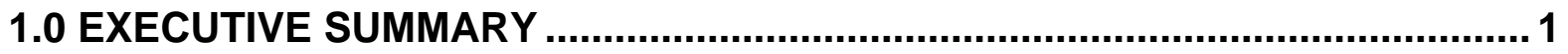

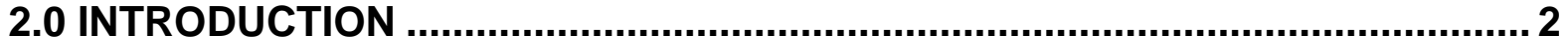

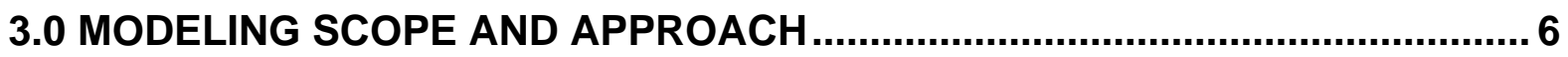

4.0 MODELING RESULTS AND DISCUSSION ............................................. 24

4.1 IN-COLUMN THERMAL MODELING RESULTS ...................................... 25

4.2 IN-TANK THERMAL MODELING RESULTS ........................................... 35

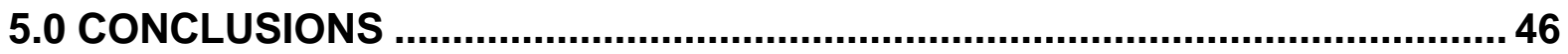

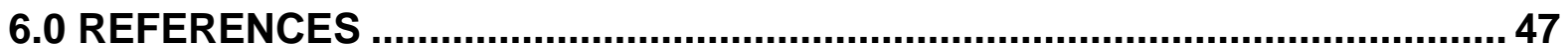




\section{LIST OF FIGURES}

Figure 1. In-column modeling domain for the ion-exchange column with CST media ...........4 Figure 2. Three-dimensional modeling boundary for the in-tank modeling calculations in the Tank 41 facility

Figure 3. Schematic of the small column ion exchange CST bed system ....................... 17

Figure 4. Three-dimensional computational domain used for the in-column modeling calculations ............................................................................................. 18

Figure 5. Three-dimensional computational meshes used for the top and bottom regions of the in-column computational domain (about $1.0 \times 10^{6}$ mesh nodes) ..................19

Figure 6. Natural convection heat transfer correlations available in the literature showing the conservatism imbedded in the present heat transfer analysis .........................20

Figure 7. Sensitivity results associated with numerical energy residual showing that approximately $1.2 \times 10^{6}$ meshes are sufficient for the in-column analysis .........20

Figure 8. In-tank modeling geometry containing cylindrical CST mound ...........................23

Figure 9. Three-dimensional computational domain used for the in-tank modeling

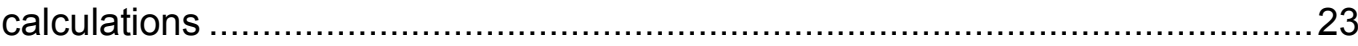

Figure 10. Three-dimensional computational meshes used for the in-tank modeling

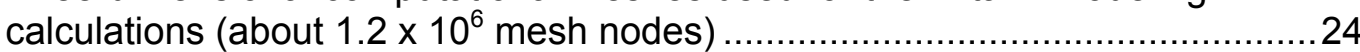

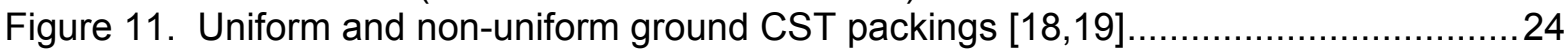

Figure 12. Flow patterns and temperature distributions for the vertical center plane of the SCIX CST bed during the normal operating conditions with $488.8 \mathrm{Ci} /$ liter thermal loading.

Figure 13. Natural convective flow patterns and temperature distributions for the vertical center plane of the SCIX CST bed region during the inactive cooling and no solution flow conditions with $488.8 \mathrm{Ci} /$ liter thermal loading.

Figure 14. Natural convective flow distributions for the center plane of the SCIX column (488.8 Ci/liter and $35^{\circ} \mathrm{C}$ ambient temperature)

Figure 15. Temperature distributions for the center plane of the SCIX column $(488.8 \mathrm{Ci} /$ liter and $35^{\circ} \mathrm{C}$ ambient temperature)

Figure 16. Temperature distributions for the middle plane of the SCIX column $(554.5 \mathrm{Ci} /$ liter and $35^{\circ} \mathrm{C}$ ambient temperature)

Figure 17. Temperature distributions for the middle plane of the SCIX column $(600 \mathrm{Ci} / / \mathrm{iter}$ and $35^{\circ} \mathrm{C}$ ambient temperature).

Figure 18. Comparison of temperature distributions along the line A-A' between the two different soil depths under the 9 in thick ground CST mound of 675 gallons.....37

Figure 19. Velocity flow patterns and temperature distributions for the vertical middle plane crossing the center of the 225 gallon cylindrical ground CST mound with 3 in height (1200 Ci/liter)

Figure 20. Comparison of temperature distributions for three different thermal loadings along the vertical line A-A' crossing the center of the 225 gallon ground cylindrical CST mound with 3 in height

Figure 21. Comparison of temperature distributions along the vertical line A-A' between the two different cylindrical ground CST mound heights with 37 in radius corresponding to the volumes of 225 and 450 gallons

Figure 22. Maximum tank floor temperatures for different cylindrical CST mound height ...42

Figure 23. Comparison of steady-state tank floor temperature distributions for two different volumes of ground CST mound with 3 in CST height (1200 Ci/liter)....

Figure 24. Comparison of steady-state temperature distributions along the vertical line A-A' between the 9-in ground CST model with and without heat transfer at the bottom of tank (Ground CST mound loaded with $514.4 \mathrm{Ci} / \mathrm{liter}$ ). 45 


\section{LIST OF TABLES}

Table 1. Baseline modeling conditions used for the heat transfer analysis of the ion exchange column

Table 2. Material and thermal properties for heat transfer calculations of the CST, column, and soil.

Table 3. Modeling cases used for the in-column analysis............................................. 16

Table 4. Thermal loadings used for the modeling analysis ...................................... 18

Table 5. Three different heights of cylindrical ground CST mounds for various thermal

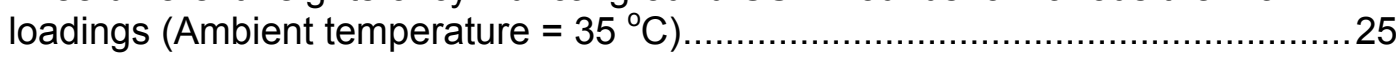

Table 6. Heat sources for different volumes of 3 -in cylindrical ground CST mounds ..........25

Table 7. Comparison of the modeling predictions and theoretical lumped model results for the baseline and bounding loading cases $\left(35^{\circ} \mathrm{C}\right.$ inlet and ambient temperatures)

Table 8. Temperatures for the porous bed and upper plenum regions of the SCIX column system.

Table 9. Temperatures for the porous bed and upper plenum regions of the SCIX column system assuming the packed bed to be conduction-controlled medium

Table 10. Bed and upper plenum temperatures of the SCIX column system for two different bed porosities.

Table 11. Quantitative comparison of maximum tank floor temperatures for two different soil boundaries under the 9 in cylindrical ground CST mound....

Table 12. Maximum tank wall temperatures for three different heights of cylindrical ground CST mounds as function of thermal loadings (Ambient temperature $=35^{\circ} \mathrm{C}$ ) .....42

Table 13. Maximum tank wall temperatures for different bed volumes of 3-in cylindrical ground CST mounds with and without NAS addition

Table 14. Maximum tank wall temperatures for different bed porosities of 3-in cylindrical ground CST mounds with and without NAS addition ..... 


\section{LIST OF ACRONYMS}

\begin{tabular}{|c|c|}
\hline$A_{w}$ & Wall surface area of bed column \\
\hline${ }^{\circ} \mathrm{C}$ & Degree Centigrade (or Celsius) \\
\hline C & Constant \\
\hline CFD & Computational Fluid Dynamics \\
\hline $\mathrm{C}_{\mathrm{p}}$ & Specific heat $(\mathrm{J} / \mathrm{kg}-\mathrm{K})$ \\
\hline$d$ & Wall thickness $(\mathrm{m})$ \\
\hline $\mathrm{D}$ & Column diameter $(\mathrm{m})$ \\
\hline $\mathrm{g}$ & Gravity $\left(\mathrm{m} / \mathrm{sec}^{2}\right)$ \\
\hline Gr & Grashof number $\left(=\frac{g \rho^{2} \beta(\Delta T) L^{3}}{\mu^{2}}\right)$ \\
\hline HLW & High Level Waste \\
\hline $\mathrm{hr}$ & Hour \\
\hline $\mathrm{h}_{\mathrm{w}}$ & Wall heat transfer coefficient (watts $/ \mathrm{m}^{2}-\mathrm{K}$ ) \\
\hline$i$ & Enthalpy (J/kg) \\
\hline in & Inch $(=0.0254 \mathrm{~m})$ \\
\hline$k_{b, \text { eff }}$ & Effective thermal conductivity for column bed (W/m-K) \\
\hline$k_{w}$ & Thermal conductivity for the column wall $(\mathrm{W} / \mathrm{m}-\mathrm{K})$ \\
\hline $\mathrm{L}$ & Length (m) \\
\hline $\mathrm{m}$ & Meter \\
\hline $\min$ & Minute \\
\hline OD & Outer diameter \\
\hline q"” & Volumetric heat source for the bed column $\left(\mathrm{W} / \mathrm{m}^{3}\right)$ \\
\hline qw" & Wall heat flux $\left(\mathrm{W} / \mathrm{m}^{2}\right)$ \\
\hline$r$ & Geometrical radius (m) \\
\hline $\mathrm{R}$ & Column inner radius $(\mathrm{m})$ \\
\hline $\mathrm{T}$ & Temperature (K) \\
\hline$\Delta \mathrm{T}$ & Temperature difference $\left(\mathrm{K}\right.$ or $\left.{ }^{\circ} \mathrm{C}\right)$ \\
\hline $\mathrm{V}_{\mathrm{b}}$ & Bed volume $\left(\mathrm{m}^{3}\right)$ \\
\hline W or watts & Power wattage (J/sec) \\
\hline$x, y, z$ & Three coordinate system for the computational domain shown Fig. 1 \\
\hline$\rho$ & Density $\left(\mathrm{kg} / \mathrm{m}^{3}\right)$ \\
\hline$\beta$ & Volumetric coefficient of thermal expansion $\left(\mathrm{K}^{-1}\right)$ \\
\hline$\theta$ & Nondimensional temperature w.r.t ambient temperature \\
\hline$\mu$ & Dynamic viscosity $(\mathrm{kg} /(\mathrm{m}-\mathrm{sec}))$ \\
\hline$\varepsilon$ & Bed porosity \\
\hline s or sec & Second \\
\hline SCFM & Standard cubic feet per minute $\left(\mathrm{ft}^{3} / \mathrm{min}\right)$ \\
\hline SCIX & Small Column Ion Exchange \\
\hline SRNL & Savannah River National Laboratory \\
\hline SRS & Savannah River Site \\
\hline
\end{tabular}




\subsection{EXECUTIVE SUMMARY}

Models have been developed to simulate the thermal characteristics of Crystalline Silicotitanate (CST) ion exchange media fully loaded with radioactive cesium packed in a column configuration or distributed on the floor of a waste storage tank. This work was conducted to support the Small Column lon Exchange (SCIX) program which is focused on processing dissolved, high-sodium salt waste for the removal of specific radionuclides such as Cs-137 within a High Level Waste (HLW) storage tank at the Savannah River Site (SRS). The column modeling domain and the scope of the calculations in this work have been broadened relative to previous calculations to include vertical temperature distributions within the packed bed of ion exchange media as well as the upper column plenum region containing only fluid. Thermal modeling calculations were also performed for the entire waste storage tank domain for the case where spent and ground CST has been transferred to the waste tank. The in-column and in-tank evaluations incorporated recently updated maximum cesium loading levels calculated using the current SCIX feed compositions, which resulted in significantly higher cesium loading than previously calculated (489 Ci/liter nominal and $600 \mathrm{Ci} / \mathrm{L}$ bounding loadings). The calculations were conducted to ensure conservative predictions for the maximum temperatures achievable using the current baseline design. However, the degree of conservatism was reduced relative to the previous two-dimensional calculations by using a three-dimensional modeling approach with the selection of parameters which were nearer to expected conditions. The primary goals of the extended thermal modeling effort were to determine whether bulk fluid boiling or superheating are possible within the column module under accident conditions and to determine the maximum floor temperatures within the tank loaded with spent CST. Accident scenarios evaluated for the column modeling calculations included loss of salt solution flow through the bed and loss of active cooling.

The calculation results showed that for a CST column with active cooling the peak temperature for the nominally-loaded column is about $38^{\circ} \mathrm{C}$ with $5 \mathrm{gpm}$ salt solution flow through the bed. For the same column filled with stagnant supernate and with inactive engineered cooling, the maximum localized temperature for the column is about $129{ }^{\circ} \mathrm{C}$. However, the volume-averaged bed temperature is $105{ }^{\circ} \mathrm{C}$, which is below the salt solution boiling point of $120^{\circ} \mathrm{C}$. In this case, the maximum temperature for the upper plenum region of the column is only $86{ }^{\circ} \mathrm{C}$. With $16 \mathrm{wt} \%$ sodium aluminosilicate addition to the CST bed (maximum media fouling level) and assuming no convective heat transfer in the bed, the maximum bed temperature was predicted to be $173{ }^{\circ} \mathrm{C}$ for the bounding loading case and the volume-averaged bed temperature was $132{ }^{\circ} \mathrm{C}$. However, the maximum temperature of the plenum in this case was only $87{ }^{\circ} \mathrm{C}$. Therefore, bulk boiling within the column is not expected even in this worst case condition.

Results for the in-tank modeling calculations clearly indicate that when realistic heat transfer boundary conditions are imposed on the bottom surface of the tank wall, a ground CST mound as high as 5 inches in an ideal cylindrical shape can be placed in the tank without exceeding the $100{ }^{\circ} \mathrm{C}$ wall temperature limit. The maximum floor temperatures were shown to be highly sensitive to the mound height and less sensitive to the cesium loading level (in the nominal to bounding range) or the total mound volume. Sodium aluminosilicate fouling of the CST mound did not significantly impact the maximum temperatures for the in-tank results. 


\subsection{INTRODUCTION}

The Small Column Ion Exchange (SCIX) project is designed to accelerate closure of High Level Waste (HLW) tanks at the Savannah River Site (SRS). The SRS tanks store HLW in three forms: sludge, saltcake, and supernate. An in-tank ion exchange process is being designed to treat supernate and dissolved saltcake waste. Through this process, radioactive cesium from the salt solution is adsorbed into Crystalline Silicotitanate (CST) ion exchange media packed within a flow-through column. A packed column loaded with radioactive cesium generates significant heat from radiolytic decay. The waste supernate solution within the ion exchange bed will boil around $120^{\circ} \mathrm{C}$. Solution superheating above the boiling point within the column could lead to violent hazardous energy releases. System heating from loaded CST is also of concern in other process modules, such as the waste tank. Due to tank structural integrity concerns, the wall temperature limit for the SRS waste tanks is $100^{\circ} \mathrm{C}$ [7]. The transfer of cesium-loaded CST to the tank could result in localized hot spots on the tank floor and walls which may exceed this limit. As a result, thermal modeling calculations have been conducted to predict the maximum temperatures achievable both in the column and in the waste tank.

As specified in the associated Technical Task Plan [1], one objective of the present work was to compute temperature distributions within the ion exchange column module under accident scenarios including loss of salt solution flow through the bed and loss of coolant system flow. The column modeling domain and the scope of the calculations in this case were broadened relative to previous two-dimensional calculations [2] to include vertical temperature distributions within the packed bed of ion exchange media as well as the upper column plenum region containing only fluid. The baseline design conditions and in-column modeling domain for the ion-exchange column module are shown in Figure 1. These evaluations assumed the maximum bounding cesium loading considered possible based on current knowledge regarding CST media and the anticipated feed compositions. Since this cesium loading was considerably higher than the nominal loading conditions in SRS waste, cases with lower loading were also evaluated. Modeling parameters were the same as those used previously unless otherwise indicated. The current model does not capture multi-phase cooling mechanisms operative when solution boiling occurs. This feature is conservative in the sense that it does not account for the large cooling effects associated with phase transfer. However, the potential transfer of heat to the plenum region associated with vertical bubble ascension through the column during boiling is also neglected.

Thermal modeling calculations were also performed for the entire waste storage tank for the case where loaded and ground CST was transferred to the tank. The modeling domain used for the in-tank calculations is provided in Figure 2. The in-tank domain is based on SRS Tank 41, which is a Type-IIIA tank. Temperature distributions were evaluated for cylindrical, ground CST mounds located on the tank floor. Media grinding is required prior to vitrification processing of the CST in the SRS Defense Waste Processing Facility (DWPF). The location of the heat source region on the tank floor due to the accumulation of CST material was assumed to be just under the grinder. The shape of the CST mound was assumed to be cylindrical. This shape is believed to be most representative of the actual mound shape formed in the tank, given that submersible mixing pumps will be available for media dispersion. Alternative configurations involving other geometrical shapes for the CST mound were evaluated in 
the previous work [2]. Sensitivity analysis for the in-tank region was performed for different amounts of CST media. As was the case for the in-column model, the in-tank model does not include multi-phase cooling mechanisms operative when solution boiling occurs.

The in-column and the in-tank evaluations incorporated recently updated maximum cesium loading levels calculated using the current SCIX feed compositions, which resulted in significantly higher cesium loading than previously calculated [6]. The calculations were conducted to ensure conservative predictions for the maximum temperatures achievable using the current baseline design. The degree of conservatism was reduced for in-column calculations relative to the previous work $[2,3]$ by using a three-dimensional modeling approach and selecting parameters which were nearer to expected conditions. The degree of conservatism for the in-tank calculations was also reduced by lowering the soil penetration depth below the tank from 150 to 20 feet. The primary goals of the extended thermal modeling effort were to determine whether fluid boiling or superheating are possible within the column module and to determine the maximum floor temperatures within the tank loaded with spent CST. For any results in which the maximum temperatures exceed the solution boiling point of $120^{\circ} \mathrm{C}$, consideration should be given to the fact that the model does not capture the cooling and heat transfer effects associated with phase transitions. For this reason, the volume-averaged temperature of the ion exchange bed is provided in many cases, since it is expected that localized boiling will tend to quickly subside as the heat is transferred into the bulk surrounding bed volume.

In-column and in-tank calculations were also conducted simulating a CST bed fouled with sodium aluminosilicate (NAS) solids. Sodium aluminosilicate (specifically cancrinite) solids have been shown to precipitate on CST from waste supernate solutions. NAS precipitation can lead to bed fouling and reduced porosity as exhibited by increased hydraulic pressure drops across packed columns. To ensure conservatism, the calculations assumed that the entire CST bed contains 16 wt. \% cancrinite, even though typical NAS fouling occurs primarily in the top of the bed. 


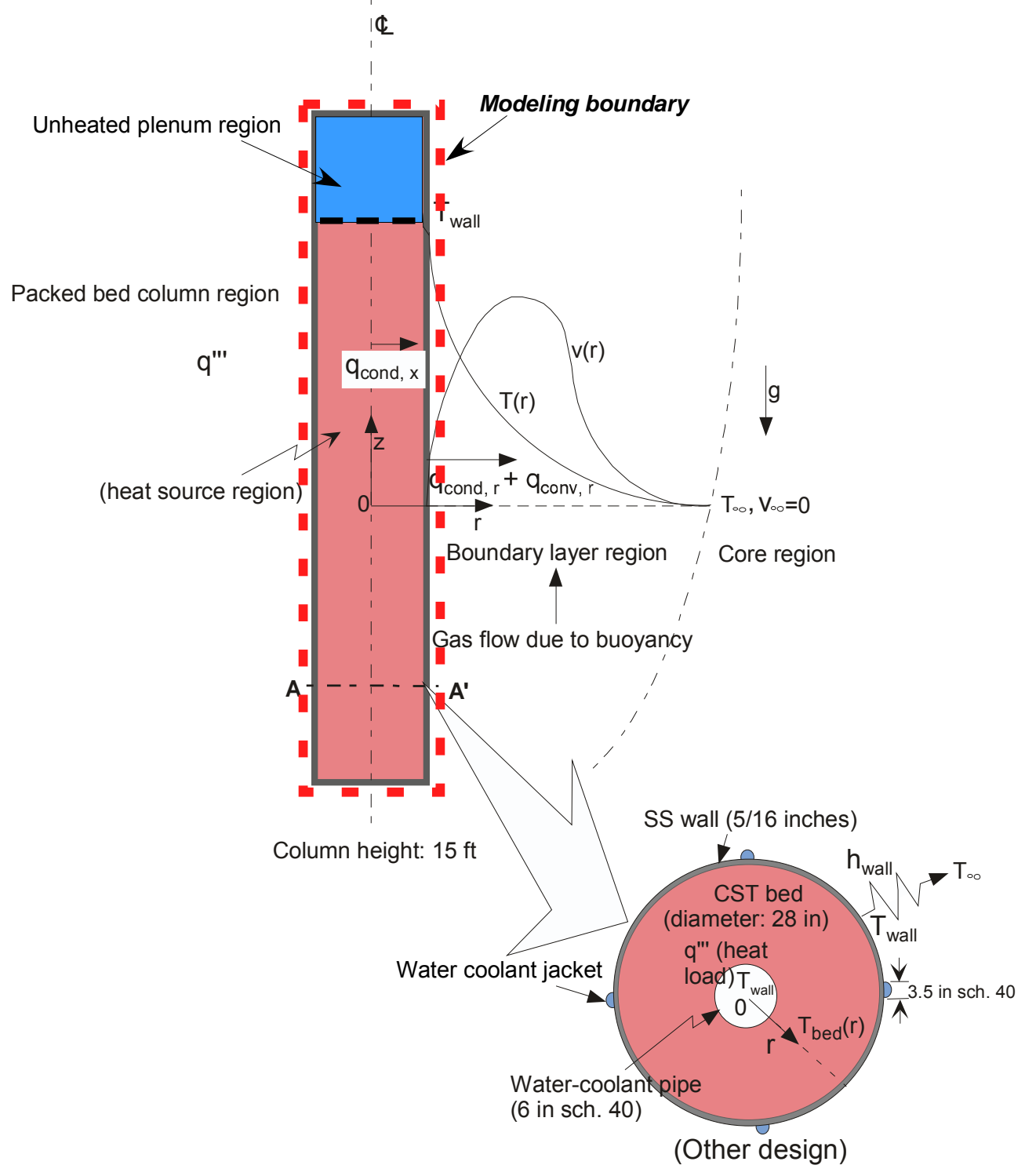

(A-A' cross-sectional plane)

Figure 1. In-column modeling domain for the ion-exchange column with CST media 


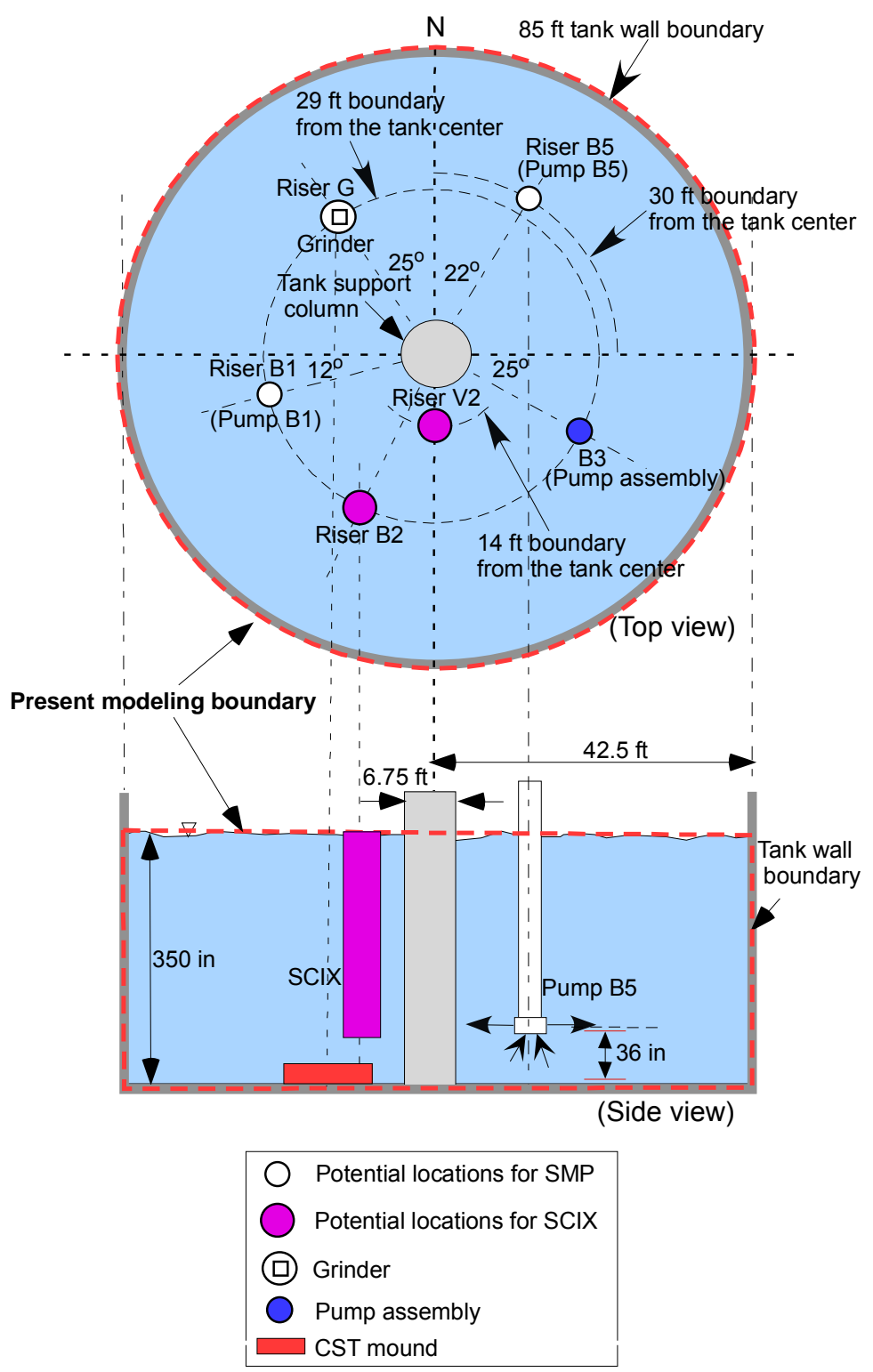

Figure 2. Three-dimensional modeling boundary for the in-tank modeling calculations in the Tank 41 facility 


\subsection{MODELING SCOPE AND APPROACH}

The SCIX modeling and analysis scope included two separate domain areas. One involved the in-column heat transfer analysis for an ion exchange column containing CST and salt solution. The other was an in-tank domain which included the entire waste tank with accumulated spent CST material on the floor.

The SCIX in-tank cesium-removal system contains two ion-exchange column modules and one IX media grinder inside an 85-ft diameter SRS Type-IIIA tank. The column module is designed for cesium removal from an SRS High-Level Waste (HLW) salt solution containing numerous radioactive species. The columns are packed with Crystalline Silicotitanate ion exchange media. The baseline design includes a 14 foot tall column with an annular design which contains about 402 gallons of CST media. The supernate is an alkaline, concentrated sodium salt solution (nominally $6 \mathrm{M} \mathrm{Na}^{+}$). Through this process, radioactive cesium from the salt solution is adsorbed onto the ion exchange media, which is packed within the flow-through column. The packed ion exchange column loaded with radioactive cesium $\left(\sim 9.0 \times 10^{5} \mathrm{Ci}\right)$ generates significant heat from radiolytic decay. Under normal operating conditions, process fluid flow through the column can provide adequate heat removal from the system through a coupled conduction and convection heat transfer mechanism. However, in the case of loss of solution flow in the column, there are safety concerns about the maximum temperatures observed in the fully-loaded column with and without active cooling. In particular, the waste supernate solution will boil within the column around $120^{\circ} \mathrm{C}$. The baseline design for the column module shown in Fig. 1 is used as the calculation domain. Previous sensitivity analyses with respect to the baseline results were performed in order to identify the key parameters that significantly impacted the thermal performance inside the column. The baseline modeling conditions used for the incolumn analysis are provided in Table 1.

For computational modeling purposes, a conservative approach was taken by assuming that the primary cooling mechanism inside and outside of the stagnant column with no active cooling is a natural convection. Axial heat removal from the column due to buoyancy effects are also considered via the Boussinesq approximation. A threedimensional steady-state heat conduction-convection coupled model was developed to assess the thermal performance of the CST column with loss of flow using the prototypic geometry. The model was created using the body-fitted coordinate system and structured multi-block grids in the Computational Fluid Dynamics (CFD) preprocessing environment. Heat transfer analysis of the CST column is performed for a given boundary condition by using a computational heat transfer approach on a Cartesian $\mathrm{x}-\mathrm{y}$ grid under the commercial CFD code, FLUENT environment. The computational geometry for the SCIX column design shown in Fig. 3 was created by using the FLUENT preprocessor. The corresponding computational domain presented in Fig. 4 indicates that about $1.2 \times 10^{6}$ mesh nodes are needed for the in-column thermal analysis. The actual computational meshes used for the analysis are shown in Fig. 5.

The in-column model considers two basic process scenarios. One case involves a packed CST bed filled with salt solution under normal operating conditions, while the other involves a packed CST bed filled with salt solution but with loss of solution flow. The stagnant column could potentially result from operational accidents such as loss of pump flow. Spherical CST particles are assumed to be homogeneously packed inside a 
stainless steel cylinder that is 28 inches in diameter with a 0.5 inch thick wall. Detailed material and thermal properties for the CST column are summarized in Table 2. The CST packed bed porosity was estimated to be about $43.2 \%$ based on ORNL measurements [7,11]. Although the present analysis used $43.2 \%$ void fraction as the nominal value, sensitivity analysis for $50 \%$ porosity was performed since the void volume fraction of the packed bed has a substantial impact on estimations of the thermal conductivity of a composite mixture. The previous work [8] used $50 \%$ void fraction as an upper bounding estimate of the cesium loading inside the bed.

Modeling calculations for the in-column analysis were based on a three-dimensional approach involving the following assumptions (unless otherwise indicated) in order to ensure conservative results for the maximum temperatures.

- The column is filled with a fixed, packed bed of CST particles with homogeneous packing.

- The CST bed is immersed in salt solution with no active fluid flow through the bed. One analysis case involved nominal fluid flow through the bed.

- The CST particle and salt solution are in local thermal equilibrium so that an average effective thermal conductivity can be assumed for the packed bed.

- The column is suspended in unventilated dry air at $35^{\circ} \mathrm{C}$ rather than salt solution within the High Level Waste tank head space.

- The bounding heat source term used of $600 \mathrm{Ci} / \mathrm{L}$ of packed bed is $123 \%$ of the nominal cesium loading of $488.8 \mathrm{Ci} / \mathrm{L}$ predicted for the various SRS waste compositions recently considered for SCIX processing [8]. The heat source was calculated assuming secular equilibrium involving ${ }^{137} \mathrm{Cs}$ and ${ }^{137 \mathrm{~m}} \mathrm{Ba}$ decay. The heat source is assumed to be uniformly distributed throughout the entire packed column as would be expected for cesium-saturated media. This Curie loading corresponds to $2.97 \mathrm{~kW} /$ liter.

- Outside the column there is no forced convective airflow, so natural convection is the primary heat transfer mechanism from the exterior column wall. Radiative cooling contributions at the outer wall surfaces of the column are also considered.

- A typical natural convective heat transfer coefficient $\left(h_{w}\right)$ of $4 \mathrm{~W} / \mathrm{m}^{2} \mathrm{~K}$ was used as an external wall boundary condition based on the literature [12].

Using the modeling boundary shown in Fig. 1 and the computational mesh shown in Fig. 5 , the in-column modeling calculations were performed for a range of conditions to conservatively estimate maximum temperatures. The in-column modeling conditions used for the present analysis are summarized in Table 3.

The governing equations to be solved for the modeling domain are one mass balance, three momentum conservations, and one fluid-solid mixture energy balance along an $x-$, $y-$, and $z$ - coordinate system for the modeling domain. Although the flow regime is in laminar-turbulent transition, modeling calculations with a laminar cooling mechanism were performed for conservatism. Another reason for the laminar approach is that the impact of turbulent eddies on column cooling was not quantified.

The finite volume method was used with the adoption of an iterative approach based on a semi-implicit method for pressure-linked equations (SIMPLE) of pressure-velocity 
coupling. The gird distribution was non-uniform with a smaller mesh size for the cell regions of the SCIX system as shown in Fig. 3. The present solution is not sensitive to the grid size when the number of total cells is higher than $1.2 \times 10^{6}$ for the modeling domain. The iterative solution was considered converged when the normalized residual errors of all the independent variables solved were reduced at least by three orders or magnitude and the total energy residual was less than 0.5 watts. The values of other variables were also monitored during the iteration to ensure convergence of all of the variables. All governing equations and constitutive relations to be solved for the CFD domain are shown in eqs. (1) to (7).

Mass conservation equation:

$$
\nabla \cdot(\rho \vec{v})=0
$$

Momentum conservation equation:

$$
\nabla \cdot(\rho \vec{v} \vec{v})=-\nabla p+\nabla \cdot(\bar{\tau})+\rho \vec{g}+\vec{F}
$$

\section{Energy conservation equation:}

$$
\nabla \bullet\left\{\vec{v}\left(\rho h_{m}+0.5 \rho v^{2}\right)\right\}=\nabla \bullet\left(k_{h, \text { eff }} \nabla T\right)+q^{\prime \prime \prime}
$$

The flow through porous media was considered as a momentum sink term. The porous media model incorporates an empirically determined flow resistance in an isotropic porous region. In essence, the isotropic porous media model is an added momentum sink in the governing momentum equation eq. (2).

\section{- Momentum Source Term in Flow Momentum Equation, $F$}

The present model calculates the superficial velocity based on the volumetric flow rate. The momentum sink term is composed of two parts, a viscous loss term and an inertial loss term. It was based on Ergun's equation [3].

$$
F_{i}=-\left(\frac{\mu}{\alpha} v_{i}+\frac{1}{2} C \rho v_{i}^{2}\right)
$$

where $\alpha=-\left(\frac{d_{p}^{2} \varepsilon^{3}}{150(1-\varepsilon)^{3}}\right)$, and $C=-\left(\frac{3.5(1-\varepsilon)}{d_{p} \varepsilon^{3}}\right)$.

$F_{i}$ in eq. (4) is the momentum sink term in the direction $\mathrm{i}$, where $\mathrm{i}=1,2$, or 3 , corresponding to the $\mathrm{x}-, \mathrm{y}-$, and $\mathrm{z}$-directions, respectively. The coefficients $\alpha$ and $C$ were determined from the literature.

\section{- Energy Balance Equation in Porous Media}

The present model calculates the energy transport equation given by eq. (3) in the porous zone with modifications to the conduction heat flux only. The last term on the right-hand side of eq, (3) represents the energy source term, $q_{s}$, corresponding to the thermal loading of the CST bed. Total convective energy in the spatial derivative is used 
as the fluid-solid mixture energy, which is homogeneously mixed in terms of porosity. Thermal conductivity, $k_{h, \text { eff, }}$ used in the conduction heat flux is used as a homogeneous mixture of fluid and solid conductivities.

$k_{h, \text { eff }}=\varepsilon k_{f}+(1-\varepsilon) k_{s}$

$k_{f}$ and $k_{s}$ in eq. (5) are thermal conductivities for fluid and solid materials in porous media, respectively, assuming isotropic thermal contributions of solid material to the continuous fluid medium.

For the natural convective cooling calculations of the porous bed region, the Boussinesq approximation was used for the gravitational term in the momentum equation to include buoyancy-induced natural convection. A two-part approximation was used which neglects all variable property effects in the governing equations and approximates the density difference term with a simplified equation of state. The gravity term in the vertical direction, $X_{3}=-\rho g$, in eq. (2) was replaced by the following relation:

$$
\rho g=\rho_{\infty}\left\{1-\beta\left(T-T_{\infty}\right)\right\} g
$$

Detailed geometrical configurations for the SCIX column including the CST region are shown in Fig. 3.

For the baseline in-column analysis, the column was assumed to be cooled by natural convection. The heat transfer coefficient at the outside wall of the column $\left(h_{w}\right)$ was obtained by using an empirical correlation available in the literature. In this situation, the natural convection flow regime for the air-cooled design should be estimated based on the non-dimensional Grashof number $\left(\mathrm{Gr}_{\mathrm{L}}\right)$, which is the parameter describing the ratio of buoyancy to viscous forces for a vertically-oriented cylinder with height $L$. The Grashof number performs much the same function for natural convection flow as the Reynolds $(\mathrm{Re})$ number does for forced convection. Under normal conditions one may expect that the laminar-to-turbulent transition will take place between $G_{L} \approx 10^{9}$ and $10^{10}$ [9]. For a conservative thermal evaluation, the flow regime of the column driven by buoyancy was assumed to be laminar.

A typical natural convective heat transfer coefficient $\left(h_{w}\right)$ of $4 \mathrm{~W} / \mathrm{m}^{2} \mathrm{~K}$ was used as an external wall boundary condition from the literature $[12,13]$. The value of the heat transfer coefficient can be justified on the following basis.

For a conservative calculation, a low temperature gradient at the wall boundary layer was used to estimate the natural convection capability for the present geometrical configurations. The heat transfer coefficient $\left(h_{w}\right)$ for natural convective cooling under a turbulent flow regime $\left(\mathrm{Ra}_{f}=\mathrm{Gr}_{L} \mathrm{Pr}_{f}>10^{9}\right)$ is given in terms of non-dimensional numbers empirically, as:

$$
N u_{L}=\frac{h_{w} L}{k_{w}}=C\left(G r_{L} \operatorname{Pr}_{f}\right)^{m} \quad \text { for } \operatorname{Gr}_{L} \operatorname{Pr}_{f}<10^{12}
$$

where $\mathrm{C}$ and $\mathrm{m}$ are the coefficients determined from literature data and $L$ is the characteristic length of the CST column. 
For the present geometrical configuration, $\mathrm{C}=0.10$ and $\mathrm{m}=0.333$ are given by Warner and Arpaci using the experimental data [12]. From eq. (7), the heat transfer coefficient $\left(h_{w}\right)$ is about $4 \mathrm{~W} / \mathrm{m}^{2} \mathrm{~K}$ corresponding to $N u_{L} \approx 570$ for typical operating conditions. Figure 6 shows the quantified results for the literature correlation based on laminar natural convection, which was developed by Warner and Arpaci. The figure shows the conservatism imbedded in the present modeling conditions involving natural convection through the exterior wall surface of the CST column.

In the present work, some modeling cases include active engineered cooling systems with a forced convection mechanism as shown in Table 3. The CST column is cooled by forced convection through the 3.5-in water jackets attached to the exterior of the column wall and the inner surface of a 6 -in central coolant water pipe. The Reynolds number for the present analysis is about 7,000 when $6.25 \mathrm{gpm}(0.25 \mathrm{~m} / \mathrm{sec})$ flows through the 3.5-in half-moon coolant tubes. Although the coolant flow regime is at the laminar-turbulent transition, the current models were assumed to be laminar for conservatism.

For modeling case involving stagnant supernate with active flow through the inner and outer cooling tubes, approximately $60 \%$ of the heat is removed from the system through the central tube, $10 \%$ is removed by the external tubes, and $30 \%$ is removed through radiation and convective heat transfer into the plenum region and through the column walls.

The main design parameters involved for the heat transfer in a fixed bed SCIX column are as follows:

- Ambient air temperature around the column system

- Heat load of the CST column

- Porous bed thermal properties

- External and internal heat removal capability of the column such as coolant pipe size and flow conditions

Table 3 presents the modeling cases for the baseline in-column analysis of the 28-inch diameter cesium-saturated SCIX CST column. Table 4 shows a range of total heat loads generated by the SCIX column. These heat loads were used as the volumetric heat source term q"' in eq. (3) for the modeling calculations.

The solution methodology for the in-column and in-tank models has been established to calculate steady-state temperature responses of the column system to the heat load q"' under nominal and accident conditions. In this work, two temperature limits were used for the operation and safety criteria in the thermal evaluation of the SCIX system. One was an operating temperature limit of $120^{\circ} \mathrm{C}$ to prevent bulk boiling of supernate within the column. The boiling point of a typical SCIX supernate (nominally $6 \mathrm{M} \mathrm{Na}^{+}$) is $\sim 106^{\circ} \mathrm{C}$ at atmospheric pressure. However, at a pressure of 1.5 atmospheres, which is near the pressure expected in the lower portion of the bed where the highest temperatures are observed, the boiling point should increase to near $120{ }^{\circ} \mathrm{C}$. At a pressure of 2.0 atmospheres, which is near the pressure expected at the bottom of a waste tank filled with supernate, the boiling point should increase to near $129^{\circ} \mathrm{C}$. A temperature limit of $100^{\circ} \mathrm{C}$ was imposed on the tank wall material due to corrosion control requirements [6].

Complete setup of the modeling calculations requires the input parameters such as the thermal and material properties of the components, the heat source term, and the boundary conditions along with the established modeling domain. For the heat transfer 
analysis of the CST column, the governing equations are applied to the threedimensional computation domain as shown in Fig. 4 assuming that the pore volume for the column are uniformly distributed through the entire region of the bed without any channeling effects. For conservative heat transfer calculations, the heat source was estimated for a fully-loaded and uniformly-distributed bed packed with CST. The initial calculations used $448.7 \mathrm{Ci} /$ liter (2.420 watts/liter) for CST as the volumetric heat source q"' as shown in Table 4. The total power generated by the CST column was obtained by multiplying the volumetric source by the total net column volume for a $14 \mathrm{ft}$ bed height. In addition, this region was included as a porous zone and was assumed to have a constant thermal conductivity instead of considering the temperature-dependency for the steady-state energy equation. However, the model utilized temperature-dependent densities via the Boussinesq approximation to predict buoyancy-driven natural convection flows in the SCIX column system for the case with inactive coolant systems and no solution flow.

Three-dimensional steady-state conduction-convection models were performed to estimate the maximum and volume-averaged column temperatures of the CST fixed bed and to determine the thermal impact of the SCIX system in case of loss of active coolant systems and solution flow. The effective thermal conductivity of the CST bed region was estimated by a literature correlation [7]. That is, the effective thermal conductivity of the bed $\left(k_{b, \text { eff }}\right)$ was developed as a function of the bed porosity,.$\varepsilon$, in $S I$ units $(\mathrm{W} / \mathrm{mK})$ using the literature experimental data.

$k_{b, \text { eff }}=k_{f}\left(\frac{k_{\text {peff }}}{k_{f}}\right)^{A+B \log \left(\frac{k_{\text {peff }}}{k_{f}}\right)}$

where

$$
\begin{aligned}
& A=0.280-0.757 \log \varepsilon \text { and } B=-0.057 . \\
& k_{\text {peff }}=\varepsilon_{p} k_{f}+\left(1-\varepsilon_{p}\right) k_{p}
\end{aligned}
$$

In eq. (8), $k_{\text {peff }}$ is the effective thermal conductivity of a CST particle considering particle porosity, $\varepsilon_{p} . k_{f}$ in eq. (8) is the thermal conductivity of the stagnant fluid trapped inside the porous CST particle. Coefficient A is a function of the bed porosity, $\varepsilon$. The thermal conductivity of the CST particle $\left(k_{p}\right)$ is assumed to be constant for computational efficiency.

Effective material properties of the CST column are computed in terms of the bed

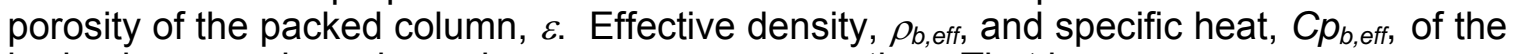
bed column are based on a homogeneous assumption. That is,

$\rho_{b, \mathrm{eff}}=\varepsilon \rho_{f}+(1-\varepsilon) \rho_{\text {peff }}$

Effective particle density, $\rho_{\text {peff, }}$, is given by the particle porosity, $\varepsilon_{p}$.

$$
\begin{aligned}
& \rho_{\text {peff }}=\varepsilon_{p} \rho_{f}+\left(1-\varepsilon_{p}\right) \rho_{p} \\
& C p_{b, \text { eff }}=\varepsilon C p_{f}+(1-\varepsilon) C p_{\text {peff }}
\end{aligned}
$$

Effective particle specific heat, $C p_{\text {peff, }}$ is given by the particle porosity, $\varepsilon_{p}$. 
In eqs. (11) through (14), subscripts $f$ and $p$ refer to the fluid and particle materials within the packed bed, respectively. Computational time can be reduced by modeling a singlematerial region with the effective thermal conductivity instead of modeling a multimaterial region composed of two different materials. This leads to a significant reduction in effort with little impact on accuracy.

In-column and in-tank calculations were also conducted simulating a CST bed fouled with sodium aluminosilicate (NAS) solids. Sodium aluminosilicate (specifically cancrinite) solids have been shown to precipitate on CST from waste supernate solutions. NAS precipitation can lead to bed fouling and reduced porosity as exhibited by increased hydraulic pressure drops across packed columns. CST chemical stability tests were conducted at Oak Ridge using an average SRS simulant composition [14]. Column tests were conducted for five to six months using baseline and caustic-washed (improved) CST. Caustic washing was developed to minimize NAS precipitation on CST. Aluminum analysis results for CST samples collected at one month intervals during column testing provided a basis for the recommendation of $16 \mathrm{wt} \%$ cancrinite as a bounding value for NAS fouling of CST. This value is twice the highest value measured for any sample. In addition, the calculations assume that the entire CST bed contains $16 \mathrm{wt}$ \% cancrinite, even though typical NAS fouling occurs primarily in the top of the bed. For computational efficiency, an effective thermal conductivity for the composite ion exchange bed was used when the bed aluminum content was increased due to cancrinite fouling. The NAS volume fraction corresponding to a weight fraction of 0.16 was calculated assuming that NAS displaced supernate solution from bed. The weight fraction $\mathrm{W}$ for the NAS solids can be converted to volume fraction $\mathrm{C}$ using eq. (15) and densities of the solution and NAS solid phases as provided in Table 2

$C=1-\left\{\frac{\left(\frac{\rho_{f}}{\rho_{s}}\right)}{\left(\frac{1}{W}-1\right)}+1\right\}^{-1}$

where $\rho_{f}$ and $\rho_{s}$ are the densities of fluid and solid, respectively.

From eq. (15) the volume fraction of NAS solids (C) was calculated to be 0.093 .

Based on the computational domain and meshes as shown in Figs. 3 and 10, the thermal performance calculations were performed by employing two temperature limits. Safety criteria limits for the column solution and tank wall temperatures are assumed to be $120{ }^{\circ} \mathrm{C}$ and $100{ }^{\circ} \mathrm{C}$, respectively. These criteria were selected to prevent waste supernate boiling and to avoid structural damage to the tanks. A temperature limit of 90 ${ }^{\circ} \mathrm{C}$ for the upper plenum region above the CST bed is also assumed for operational control. Using these temperature criteria, various thermal calculations for the in-column module and the in-tank domain were made to quantify key design and operating parameters and evaluate performance with and without engineered cooling systems. For the case of the in-tank model, a series of the modeling calculations were conducted to determine the maximum temperature of the tank wall as a function of the cylindrical CST mound volume accumulated on the tank floor.

This analysis is conservative by nature and gives reasonable temperature data. Only unventilated natural convective cooling was considered and it was assumed that the 
thermal conductivity of the CST material was constant with temperature. Additional calculations were conducted under the wet column conditions using an upper bounding cesium loading of $600 \mathrm{Ci} /$ liter. The modeling results provide quantitative information associated with process heat control and management of the SCIX design.

The three-dimensional geometry was created using the multi-block preprocessor of the Fluent $^{\mathrm{TM}}$ code [15] under the body-fitted coordinate system, which allows for the treatment of non-orthogonal geometries. For instance, the present in-column model consists of 20 element blocks and 3 different material zones on the computational domain. Non-uniform two-dimensional structured meshes of the computational domain were used to capture the smooth temperature gradient across the boundary zone of the three different material regions as shown in Fig. 4. The governing equations defined by the computational grid were solved by an iterative solution method. The detailed solution methodology was described in the previous work $[2,3]$.

The overall energy balance should be checked to demonstrate the adequacy of the grid fineness used. This was done by using eq. (16).

$$
R=-\int_{A_{W}} q_{W}^{\prime \prime} d A+q^{\prime \prime \prime} V_{b}
$$

The volumetric heat source term, q'", in eq. (16) is given by the code input. For all the cases considered here, the absolute value of the energy residual $(R)$ was maintained at a value less than 0.5 watts. For instance, the residual results for the column model with active central and external cooling systems are shown as a function of the grid number in Fig. 7. For the present analysis, an optimum grid of about $1.2 \times 10^{6}$ cells for the 28inch diameter column was established from the grid sensitivity analysis under the Linux high performance computing platform. Non-uniform three-dimensional meshes used for the computational analysis of the 28-inch diameter column are shown in Fig. 5. 
Table 1. Baseline modeling conditions used for the heat transfer analysis.

\begin{tabular}{|c|c|}
\hline Models & Conditions for the baseline model \\
\hline Column heat load & 488.8 Ci/liter (2419.6 W/m³) [8] \\
\hline CST material porosity & $24.0 \%[8]$ \\
\hline Column hydraulic conditions & no flow, or $5 \mathrm{gpm}$ flow* \\
\hline Column media & wet column* \\
\hline Granular bed conditions & fixed bed \\
\hline Ambient temperature & $35^{\circ} \mathrm{C}\left(25^{\circ} \mathrm{C}\right)^{*}$ \\
\hline $\begin{array}{l}\text { Heat transfer coefficient at } \\
\quad \text { wall, } h_{w}\left(\mathrm{~W} / \mathrm{m}^{2} \mathrm{sec}\right)\end{array}$ & $4 \mathrm{~W} / \mathrm{m}^{2} \mathrm{~K}$ (typical natural convection) $[13,14]^{\star *}$ \\
\hline $\begin{array}{l}\text { Coolant water flowrate in } \\
\text { cooling jackets }\end{array}$ & $\begin{array}{l}6.25 \mathrm{gpm} \text { each side jacket, } 12.5 \mathrm{gpm} \text { for annular central } \\
\text { coolant pipe }\end{array}$ \\
\hline Coolant water temperature & $\begin{array}{l}\text { no forced buoyancy-driven or forced convective } \\
\text { circulation }\end{array}$ \\
\hline Bed porosity & $43.2 \%[11], 50 \%{ }^{++}[8]$ \\
\hline $\begin{array}{l}\text { Thermal expansion } \\
\text { coefficient }\left(\mathrm{K}^{-1}\right)^{+}\end{array}$ & $7.0 \times 10^{-4}$ \\
\hline
\end{tabular}

${ }^{\#}$ All Curies assumed converted to heat load wattage

${ }^{*}$ Conditions to be evaluated by sensitivity analysis

${ }^{* *}$ Heat transfer coefficient at the exterior wall of the CST column

+ From http://physchem.kfunigraz.ac.at/sm/Service/Water/H2Othermexp.htm

++ For sensitivity analysis 
Table 2. Material and thermal properties for heat transfer calculations of the CST, column, and soil

\begin{tabular}{|c|c|c|c|}
\hline Material & $\begin{array}{l}\text { Thermal conductivity } \\
\qquad(\mathrm{W} / \mathrm{mK})\end{array}$ & $\begin{array}{l}\text { Density } \\
\text { (kg/m3) }\end{array}$ & $\begin{array}{c}\text { Specific heat } \\
(\mathrm{J} / \mathrm{kgK})\end{array}$ \\
\hline CST [2] & 0.1617 & $2056.3^{* *}$ & 1052.3 \\
\hline Salt Solution [2] & 0.68 & 1232.0 & 3630.0 \\
\hline Water [10] & 0.68 & 998.0 & 4216 \\
\hline CST-Salt Solution & $0.4125^{\#}$ & $\begin{array}{c}1587.8^{\#} \\
\text { (from eqn. } 8 \text { ) }\end{array}$ & $\begin{array}{l}2517.3^{\#} \\
\text { (from eqn. 9) }\end{array}$ \\
\hline $\begin{array}{l}\text { Ground CST-Salt } \\
\text { Solution }\end{array}$ & $0.3386^{\#}$ & $\begin{array}{c}1723.2^{\#} \\
\text { (from eqn. } 8)\end{array}$ & $\begin{array}{l}2094.1^{\#} \\
\text { (from eqn. 9) }\end{array}$ \\
\hline Stainless steel [20] & 17.30 & 7800.0 & 486.0 \\
\hline Concrete & 1.5 & 2400 & 750 \\
\hline Ceramic & 18.0 & 3690 & 880 \\
\hline soil & 1.25 & 2000 & 1450 \\
\hline NAS & 0.1 & 2290 & 1423.5 \\
\hline CST-NAS mixture $\$$ & 0.2599 & 1919 & 1636 \\
\hline
\end{tabular}

\# based on non-linear empirical correlation of Krupiczka at $25^{\circ} \mathrm{C}$ [15] considering particle porosities $\left(\varepsilon_{C S T}\right.$, particle $\left.=24 \%\right)$ and the volume fractions of air or fluid in the packed beds ( 0.432 for CST bed), giving total bed porosities of 0.57 for CST (total porosity evaluated considering bead and bed porosity.). In case of ground CST for the in-tank modeling analysis, porosity is assumed to be reduced by $50 \%$ from the void filling with smaller ones.

${ }^{*} \mathrm{~T}$ is absolute temperature in $\mathrm{K}[16]$

${ }^{* *}$ based on material density (not bulk density)

*** based on the condition that volume fraction of fluid or air in packed bed is 0.432 at $25^{\circ} \mathrm{C}$ temperature

$\$ 16 \mathrm{wt} \%$ replacement of nominal pore volume for sensitivity analysis 
Table 3. Modeling cases used for the in-column analysis

\begin{tabular}{|c|c|c|c|}
\hline \multirow{2}{*}{$\begin{array}{c}\text { CST loading } \\
\text { (Curie/liter) }\end{array}$} & $\begin{array}{c}\text { Column Hydraulic } \\
\text { conditions }\end{array}$ & \multicolumn{2}{|c|}{ Engineered cooling system } \\
\cline { 2 - 4 } & $\begin{array}{c}\text { Central cooling } \\
\text { system }\end{array}$ & $\begin{array}{c}\text { External cooling } \\
\text { system }\end{array}$ \\
\hline $\begin{array}{c}588.8 \\
\text { (Baseline loading) }\end{array}$ & $\begin{array}{c}5 \text { gpm flow } \\
\text { (normal operating) }\end{array}$ & Active & Active \\
\cline { 2 - 4 } & Stagnant (Wet) & Inactive & Inactive \\
\hline $\begin{array}{c}554.5 \\
\text { (Max. loading) }\end{array}$ & Stagnant (Wet) & Inactive & Inactive \\
\hline \multirow{2}{*}{$\begin{array}{c}600 \\
\text { (Upper bounding) }\end{array}$} & $\begin{array}{c}5 \text { gpm flow } \\
\text { (normal operating) }\end{array}$ & Active & Active \\
\cline { 2 - 4 } & Stagnant (Wet) & Inactive & Inactive \\
\hline
\end{tabular}




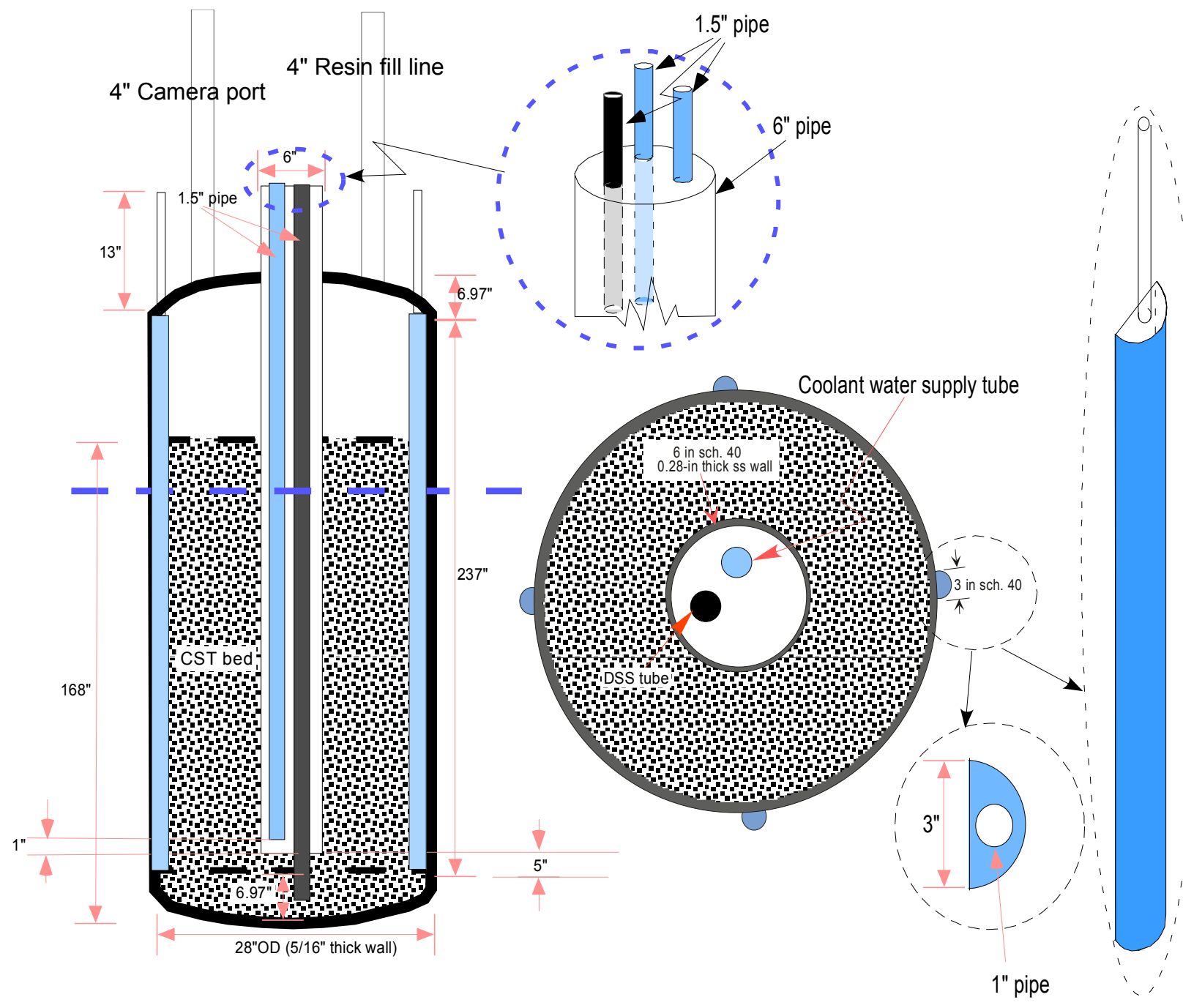

Figure 3. Schematic of the small column ion exchange CST bed system 
Table 4. Thermal loadings used for the modeling analysis

\begin{tabular}{|c|c|c|c|}
\hline SCIX Feed conditions & $\begin{array}{c}\text { Cesium loadings } \\
(\mathrm{Ci} / \text { liter })\end{array}$ & $\begin{array}{c}\text { Thermal loadings } \\
\left(\text { watts } / \mathrm{m}^{3}\right)+[\text { watts }]^{* *}\end{array}$ & Comments \\
\hline $\begin{array}{c}\text { Nominal operating } \\
\text { conditions }\left(35^{\circ} \mathrm{C}\right)\end{array}$ & 488.8 & $2419.6[3683]$ & Nominal loadings \\
\hline $\begin{array}{c}\text { SCIX Batch } 2 \text { without } \\
\text { caustic addition at } 25^{\circ} \mathrm{C}\end{array}$ & 554.5 & $2744.8[4178]$ & $\begin{array}{c}\text { Max. calculated } \\
\text { cesium loadings }\end{array}$ \\
\hline $\begin{array}{c}\text { SCIX Bounding } \\
\text { conditions at } 35^{\circ} \mathrm{C}\end{array}$ & 600.0 & $2970[4521]$ & $\begin{array}{c}\text { Bounding cesium } \\
\text { loadings }\end{array}$ \\
\hline
\end{tabular}

Note:* SRNL-STI-2011-00181 Rev. 0

+Conversion factor for Cs-137 decay heat is 0.00495 watts/Ci.

${ }^{* *}$ Based on total bed volume of 1522.4 liters

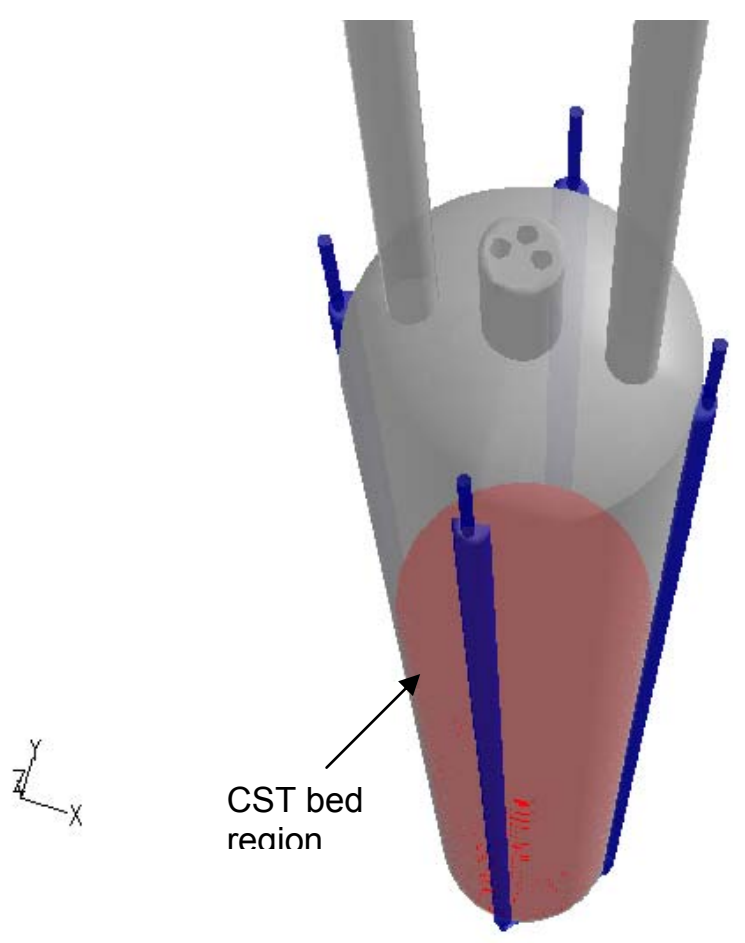

Figure 4. Three-dimensional computational domain used for the in-column modeling calculations 


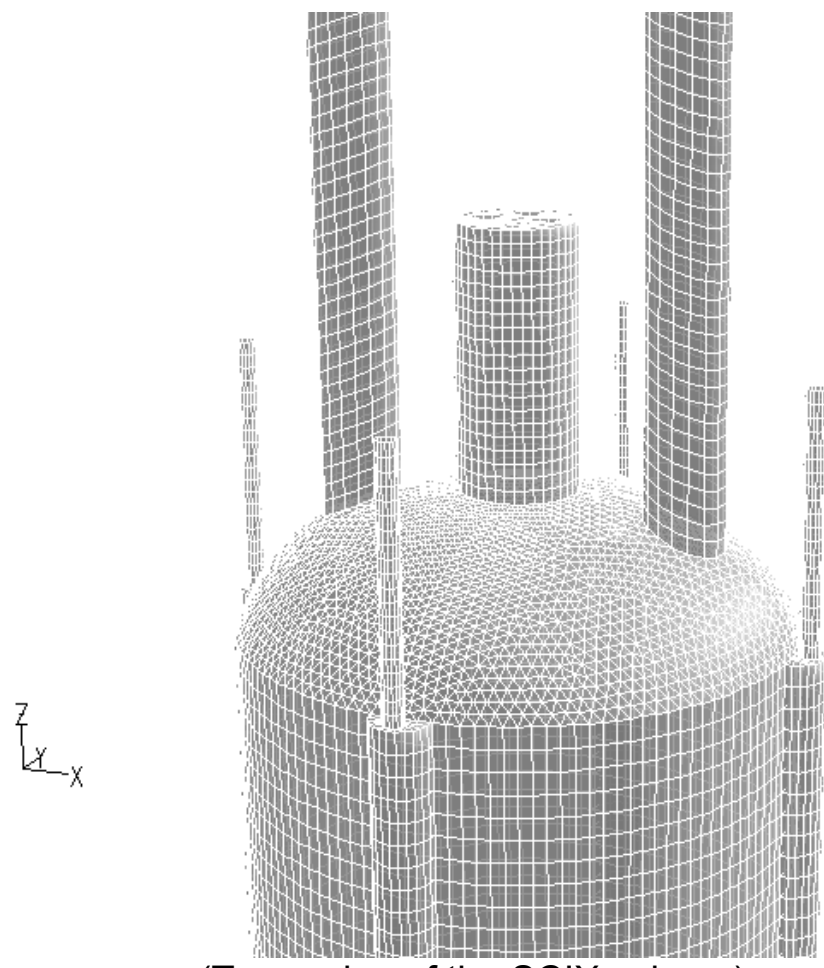

(Top region of the SCIX column)

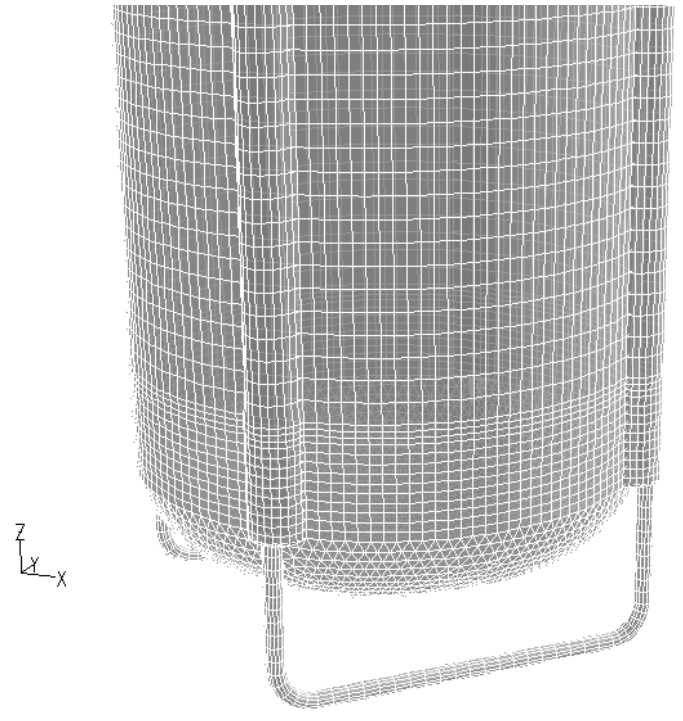

(Bottom region of the SCIX column)

Figure 5. Three-dimensional computational meshes used for the top and bottom regions of the in-column computational domain (about $1.2 \times 10^{6}$ mesh nodes) 


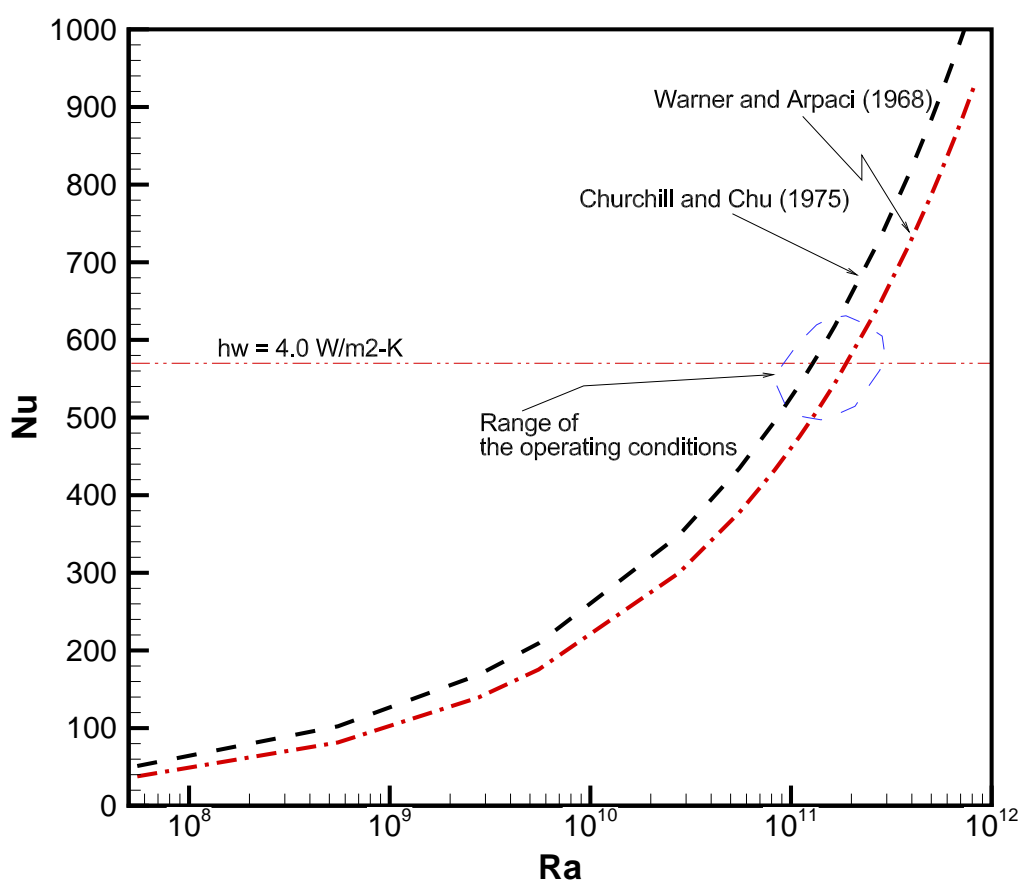

Figure 6. Natural convection heat transfer correlations available in the literature showing the conservatism imbedded in the present heat transfer analysis

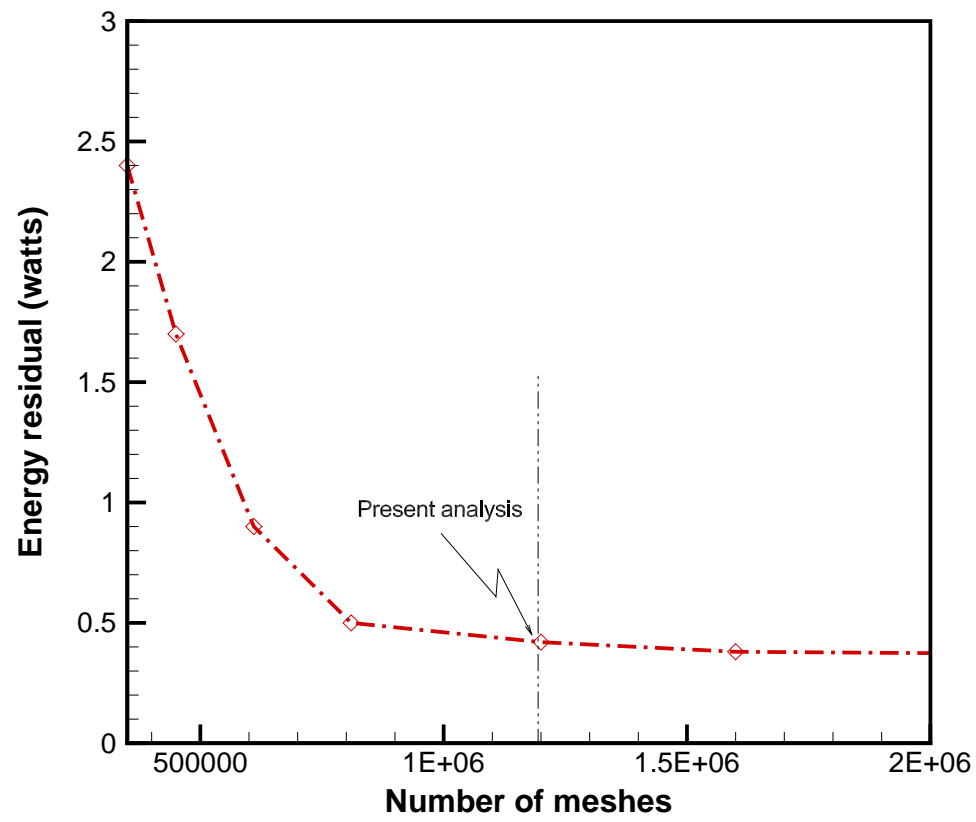

Figure 7 . Sensitivity results associated with numerical energy residual showing that approximately $1.2 \times 10^{6}$ meshes are sufficient for the in-column analysis 
When the spent CST material is dropped to the treatment tank floor as shown in Fig. 2, there are safety concerns about reaching the maximum allowable temperature at the tank wall region under the CST mound. The tank wall temperature cannot be higher than $100{ }^{\circ} \mathrm{C}$. Figure 2 shows the equipment configuration inside the SRS tank, which serves as the baseline configuration for the in-tank thermal analysis. As shown in the figure, the baseline geometrical shape of the CST mound accumulated on the tank floor was assumed to be cylindrical since previous sludge mixing studies indicated that this was the typical mound shape in the waste tanks [23]. Table 5 shows three different cylindrical heights of the CST mound used for the thermal analysis. A ground CST mound volume of 225 gallons is believed to represent one SCIX processing cycle (assuming 50\% volume reduction upon grinding).

The in-tank modeling geometry, computational domain, and computational mesh are provided in Fig. 8, 9, and 10, respectively. Although air cooling channels are shown in Fig. 8, it is not believed that significant air flow passes beneath the tank since no direct forced flow is applied to these channels. 23 cooling coils equivalent in surface area to the total heat transfer area of 548 cooling coils in Tank 41 are used as shown in Fig. 9. Material and thermal properties assumed for the in-tank calculations are provided in Table 2. Three-dimensional in-tank heat transfer models were developed to estimate the maximum temperatures for the liquid and for hot spots on the tank floor under conservative assumptions. As shown in the Fig. 10, a computational mesh containing $1.2 \times 10^{6}$ nodes was used for the final in-tank modeling calculations.

The spent CST media will be ground via a grinder module after transfer from the column module. It is expected that grinding of the material will result in a volume reduction and a change in porosity resulting from the generation of non-uniform particle size and shape distributions during the grinding process. Broadening of the particle distribution is expected to result in reduced porosity resulting from space filling of smaller particles in the voids between the larger particles, as illustrated in Fig. 11. Based on estimations from the literature $[18,19$, and 21], the void volume of the CST mound was estimated to be reduced by $50 \%$ after grinding. Thermal modeling calculations were conducted using porosity and loading values believed to be representative of the ground material. For these cases, the volumetric heat load was twice the value used for the unground material. It was therefore expected that the maximum floor temperatures observed with the ground material would be higher than were calculated for comparable geometries of unground media.

The thermal calculations for the entire in-tank domain were performed for a range of ground CST mounds. For the present analysis, a range of different CST mound heights was considered, assuming that the geometrical shape of the mound is cylindrical. Table 5 shows three different heights of cylindrical ground CST mound accumulations for each of the three different thermal loadings. Sensitivity calculations of different CST volumes for the fixed mound height and thermal loading were performed to examine the impact of the radial mound size on the tank floor temperature as shown in Table 6.

Major modeling assumptions for the in-tank calculations are as follows.

- The spent CST media was ground for the analysis cases, assuming that the mound void volume was reduced by $50 \%$ due to the presence of smaller particles. 
- The waste tank was considered full (330 inches) of stagnant $6 \mathrm{M} \mathrm{Na}^{+}$supernate with the mixing pumps turned off so that the primary cooling mechanism was natural convection due to buoyancy effects in the tank fluid with the tank cooling system serving as the primary heat transfer pathway. (Note: Previous analysis considered other tank supernate volumes [2].)

- The tank side wall boundary was cooled by ambient air via a free convectionconduction mechanism coupled with thermal radiation.

- The tank bottom wall boundary was assumed to be dissipated through the soil region such that heat transfer through the tank bottom was allowed. The calculations included heat dissipation across the tank bottom to the 20-ft deep soil region based on the previous work [24].

- Supernate was maintained as a single phase for simplification and conservatism even if local water temperatures near the CST mound exceeded the supernate boiling point in the waste tank of $129^{\circ} \mathrm{C}$.

- Inlet temperatures for coolant water and solution as well as ambient air were $35^{\circ} \mathrm{C}$.

- The tank wall thickness was assumed to be a constant value of 0.5 inches.

- 23 equivalent cooling coils corresponding to the total cooling surface area of the entire submerged cooling system (548 tubes, 2-in. diameter) in Tank 41 were evenly distributed across the tank fluid region.

- The cooling coil wall surface temperature was kept constant at $35^{\circ} \mathrm{C}$.

- The baseline heat loading for the in-tank ground CST mound was assumed to be twice the nominal bed loading of $488.8 \mathrm{Ci} /$ liter.

For calculations involving NAS material mixed with ground CST, the sludge thermal loading was conservatively estimated using a heat loading calculated for a CST/NAS/supernate mixture containing 16 wt. \% NAS. Assuming that 16 wt. \% NAS occupies $9.3 \%$ by volume in the mound solution uniformly, a thermal conductivity of 0.26 $\mathrm{W} / \mathrm{m}-\mathrm{K}$ for the NAS-CST combined material was calculated and used for the thermal modeling calculations as shown in Table 2. 


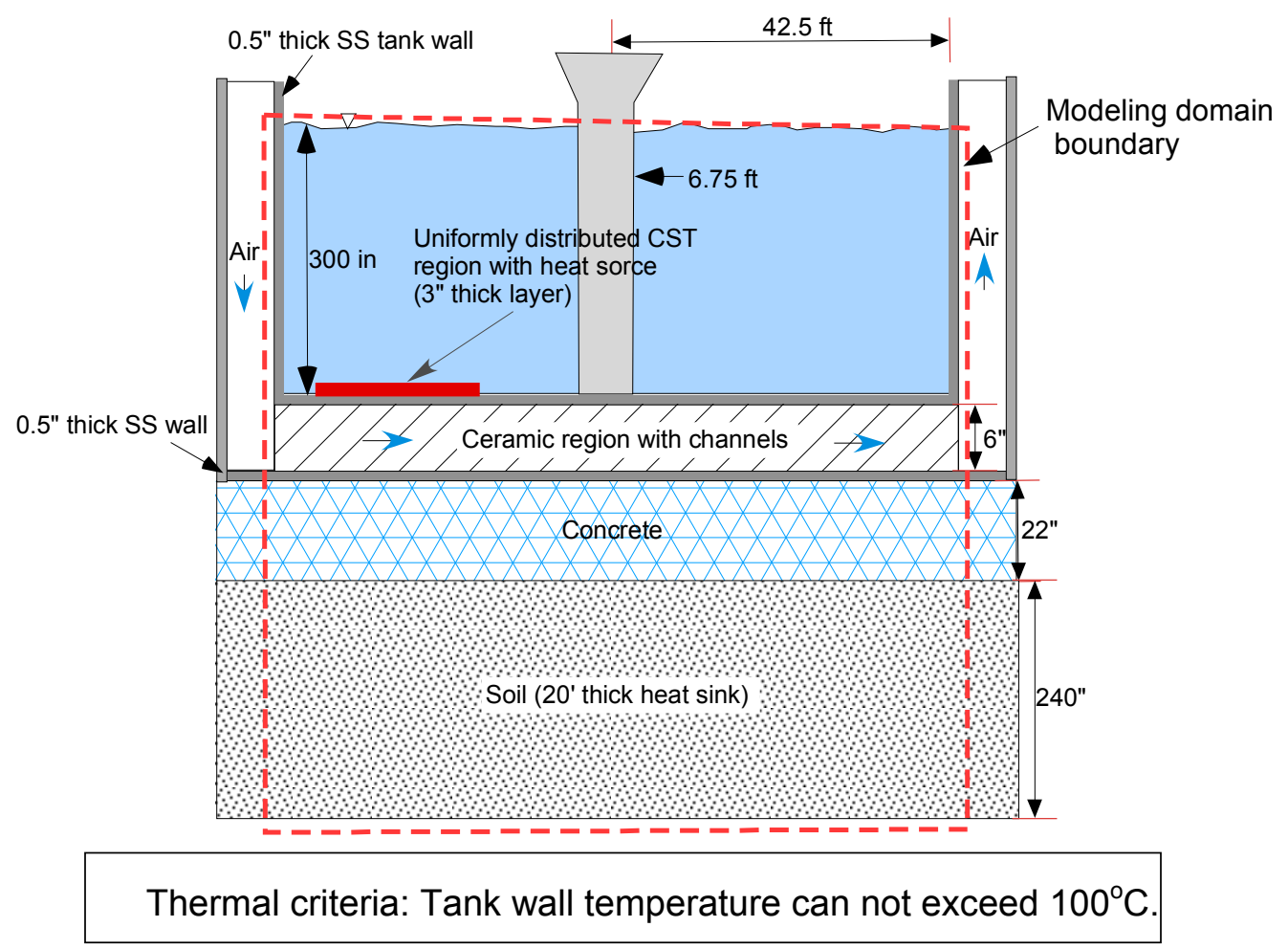

Figure 8. In-tank modeling geometry containing cylindrical CST mound

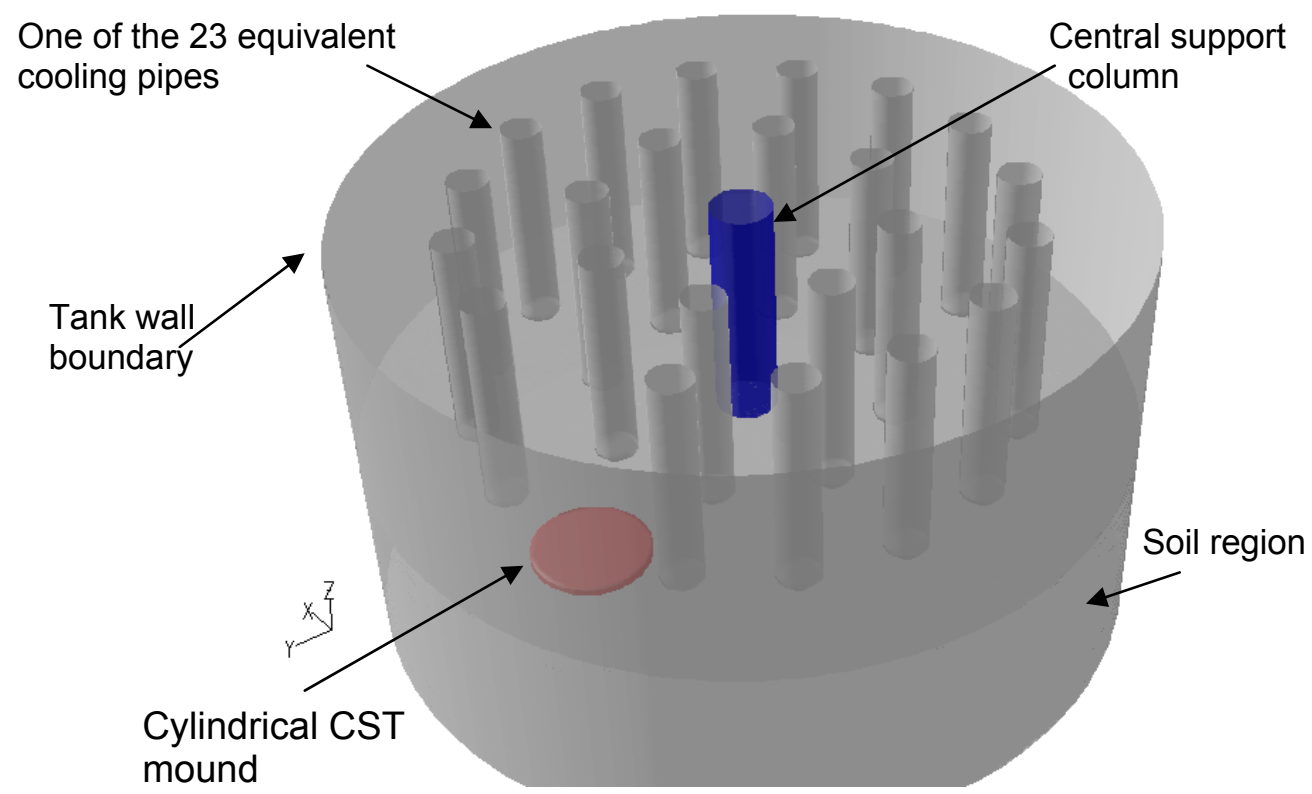

Figure 9. Three-dimensional computational domain used for the in-tank modeling calculations 


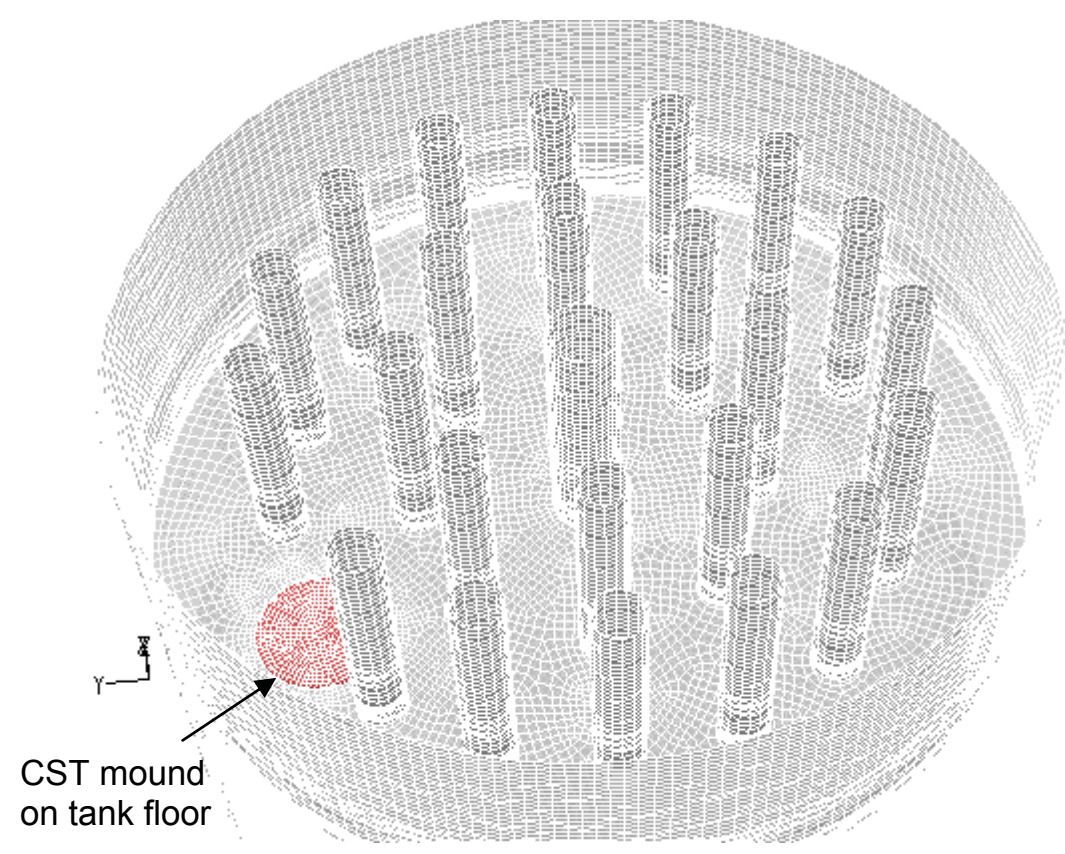

Figure 10. Three-dimensional computational meshes used for the in-tank modeling calculations (about $1.2 \times 10^{6}$ mesh nodes)

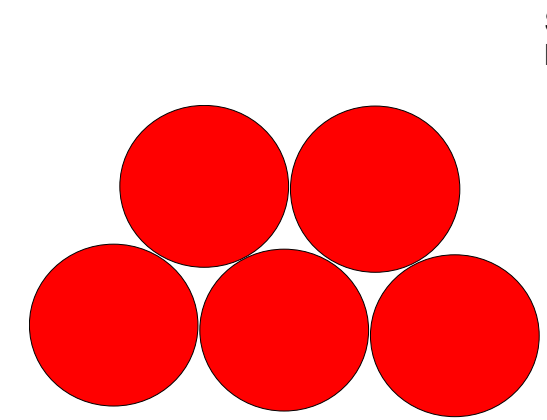

(CST packing with uniform original sizes)
Small particles reduces the porosity by filling the voids among the large particles.

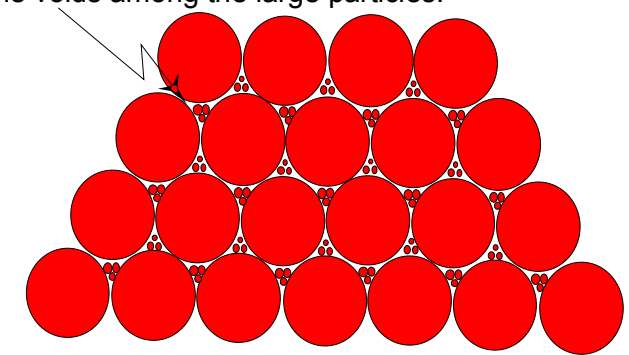

(Ground CST packing with non-uniform sizes)

Figure 11. Uniform and non-uniform ground CST packings $[18,19]$ 
Table 5. Three different heights of cylindrical ground CST mounds for various thermal loadings (Ambient temperature $=35^{\circ} \mathrm{C}$ )

\begin{tabular}{|c|c|c|c|c|}
\hline \multicolumn{2}{|c|}{$\begin{array}{c}\text { Thermal loading for ground } \\
\text { CST }\end{array}$} & \multicolumn{3}{c|}{$\begin{array}{c}\text { Total volume* for cylindrical ground CST } \\
\text { mound heights (gallons) }\end{array}$} \\
\hline Loading cases & Ci/liter & 3 inches & 6 inches & 9 inches \\
\hline Nominal loading & 977.6 & 225 & 450 & 675 \\
\hline Max. loading & 1109.0 & 225 & 450 & 675 \\
\hline Bound loading & 1200.0 & 225 & 450 & 675 \\
\hline
\end{tabular}

Note:*Based on 74 in mound radius on the tank floor

Table 6. Heat sources for different volumes of 3-in cylindrical ground CST mounds

\begin{tabular}{|c|c|c|c|}
\hline $\begin{array}{c}\text { Volume of 3-in } \\
\text { height CST } \\
\text { mound } \\
\text { (gallons) }\end{array}$ & $\begin{array}{c}\text { Volumetric heat } \\
\text { source for ground } \\
\text { CST } \\
(\text { Ci/liter })\end{array}$ & $\begin{array}{c}\text { Tank floor surface } \\
\text { area occupied by } \\
\text { CST mound } \\
\mathrm{ft}^{2}\left[\mathrm{~m}^{2}\right]\end{array}$ & $\begin{array}{c}\text { Total heat source } \\
\text { to be cooled } \\
(\mathrm{kw})\end{array}$ \\
\hline 225 & 1200 & $120.6[11.2]$ & 5.059 \\
\hline 2100 & 1200 & $1122.7[104.3]$ & 47.219 \\
\hline
\end{tabular}

\subsection{MODELING RESULTS AND DISCUSSION}

The present thermal modeling calculations primarily consist of two modeling domains. One domain involves the in-column heat transfer analysis case shown in Fig. 1. The other domain involves the in-tank analysis with ground CST media on the tank floor shown in Figs. 2 and 8 . The established meshes for these corresponding computational domains are shown in Figs. 5 and 10, respectively. Material and thermal properties used for the calculations are shown in Table 2. For in-column cases involving stagnant liquid, convective heat transfer mechanisms associated with movement of the mobile liquid phase within the column were considered in some cases. This modeling approach is considered to give more realistic predictions of the temperatures within the column. Calculations were also conducted without convective heat transfer to provide results that were more conservative. The external wall surface of the column was cooled by natural convection coupled with radiation. For the baseline in-column case, the column was assumed to be cooled by forced convective cooling through the central cooling tube and the four external cooling tubes with natural convection cooling of the remaining column wall portions. In this case, solution flow of $5 \mathrm{gpm}$ through the SCIX column was considered by taking a homogeneous porous media approach. Detailed cases for the in-column evaluations are shown in Table 3. A constant ambient temperature of $35^{\circ} \mathrm{C}$ was assumed for all modeling cases. For both in-column and in-tank modeling, nominal cesium loading on original CST was assumed to be $488.8 \mathrm{Ci} / \mathrm{L}\left(2419.6\right.$ watts $\left./ \mathrm{m}^{3}\right)$ based 
on recent work which indicated that this was the highest loading for the nominally anticipated feeds [8]. A project decision was then made to utilize a feed qualification program to control the cesium loading to $600 \mathrm{Ci} / \mathrm{L}$. All subsequent thermal modeling calculations were performed for a range of nominal $(488.8 \mathrm{Ci} /$ liter $)$ to upper bounding (600 Ci/liter) loading values.

The thermal analyses and evaluations were made by applying two temperature limits to the modeling domain as safety criteria. The safety criteria for the column and tank wall temperatures are assumed to be 120 and $100^{\circ} \mathrm{C}$, respectively. A temperature limit of 95 ${ }^{\circ} \mathrm{C}$ for the tank liquid inside the upper bed plenum is also assumed for operational control.

Benchmarking of the performance models against literature/theoretical results to verify the computational results will be conducted separately.

\subsection{IN-COLUMN THERMAL MODELING RESULTS}

For computational modeling purposes, a conservative approach was taken for stagnant flow cases with no active cooling by assuming that the primary cooling mechanism inside and outside of the column was natural convection coupled with conduction. Three-dimensional modeling calculations were conducted which included axial heat removal (end effects) from the column viand, in some cases, buoyancy-driven natural convective heat transfer to reduce the level of conservatism relative to previous calculations.

A 28-inch diameter CST column was assumed which was saturated with cesium and contained one central and four active external cooling tubes. The central cooling tube included inner coolant supply/return tubes and a decontaminated salt solution return line which is consistent with the current SCIX design specifications. The column plenum region containing only liquid and the selected piping above the plenum were included in modeling domain to capture the cooling effects from these regions. Figure 12 shows the modeling results and steady-state temperature distributions of the fully-loaded CST column under normal operating conditions with $5 \mathrm{gpm}$ salt solution flow and central coolant flow of $12.5 \mathrm{gpm}$ and side jacket coolant flow of $6.25 \mathrm{gpm}$. The figure illustrates the flow patterns and temperature distributions for coolant and salt solution for the lower bed region.

For model verification purposes, separate lumped average calculations were conducted to determine the temperature of the solution exiting the column for cases involving salt solution flow through the bed. When the SCIX column loaded with $488.8 \mathrm{Ci} /$ liter is maintained adiabatically, the lumped heat balance becomes

$Q=\rho_{f} \dot{V} C_{p f}(\Delta T)_{\text {Bulk }}$

When solution flowrate $\dot{V}$ is constantly provided to the CST column, $Q$ and $(\Delta T)_{B u l k}$ in eq. (17) are total heat load and bulk temperature increase due to the thermal load in the bed, respectively. From eq. (17), the average bulk temperature of the bed solution is increased by $2.9^{\circ} \mathrm{C}$ when the inlet temperature is $35^{\circ} \mathrm{C}$ and the loading is $488.8 \mathrm{Ci} /$ liter. The three-dimensional modeling results indicate a $2.1^{\circ} \mathrm{C}$ increase in the salt solution temperature, which is about $0.8{ }^{\circ} \mathrm{C}$ lower than the theoretical value because of heat dissipation through the wall boundary of the column system. The theoretical lumped 
calculations are therefore generally consistent with the three-dimensional model calculations.

The steady state lumped and three-dimensional model calculation results for cases involving salt solution flow are compared in Table 7 for the nominal and bounding loading conditions. The table also includes cases with no active cooling and no salt solution flow where convective heat transfer is allowed in the bed region. The results for the bounding loading of $600 \mathrm{Ci} /$ liter are higher than the nominal case as expected. For cases where salt solution flow is allowed through the bed, the differences are small because flow through the bed is so effective at removing heat from the column. Without active cooling and without salt solution flow through the bed, the maximum bed temperatures are much higher $\left(129^{\circ} \mathrm{C}\right.$ for nominal and $150{ }^{\circ} \mathrm{C}$ for bounding loadings) and exceed the solution boiling point in each case. However, it is expected that localized boiling within the column would result in rapid dispersion of the heat throughout the surrounding bed. As a result, volume-averaged bed temperatures are provided which are believed to more accurately represent the conditions within the column. Flow patterns and temperature distributions for the central region of the CST bed are shown in Fig. 13 for the case with no active cooling and no salt solution flow. The natural convective flow and temperature distributions for the entire region of the stagnant, nominally loaded CST column without active cooling including the upper plenum region are shown in Figs. 14 and 15, respectively. The results show that the upper plenum region is thermally well mixed by Benard-type natural convective mixing.

Sensitivity analysis was performed for different conditions. Steady-state temperatures for various loading levels and column loadings are provided in Table 8 for the case with no active cooling, no salt solution flow, and with convective heat transfer allowed in the bed region. In all cases, the upper plenum temperature remains below the salt solution boiling point. When the column heat load was increased by about $23 \%$ from the nominal value of $488.8 \mathrm{Ci} /$ liter to the upper bounding value of $600 \mathrm{Ci} /$ liter, the maximum column temperature increased by about $14^{\circ} \mathrm{C}$. Decreasing the ambient temperature from 35 to $25{ }^{\circ} \mathrm{C}$ resulted in a decrease in the maximum column temperature of about 8 ${ }^{\circ} \mathrm{C}$. Temperature distributions for the entire column domain with loadings of 554.5 and $600 \mathrm{Ci} /$ liter are shown in Figs. 16 and 17, respectively, where local hot spots inside the bed which exceed the salt solution boiling point are indicated. Maximum column temperatures were also estimated for different column media with inactive engineered cooling and a stagnant column. Table 8 compares the steady-state maximum column temperatures for two different bed media, original CST and CST combined with $16 \mathrm{wt} \%$ NAS (wt\% based on CST mass). As shown in the table, the calculation results show that for the NAS/CST mixture the maximum column temperature increases by about 8 ${ }^{\circ} \mathrm{C}$, while the average temperature for the upper plenum increases by only $2{ }^{\circ} \mathrm{C}$.

Calculations were also conducted in which the CST bed region was treated as a conduction-controlled media such that the solution in the porous bed was effectively frozen. It was expected that the predicted bed temperatures for the effective conduction media would be higher than was observed for cases where convection was allowed. Table 9 shows that the maximum temperatures for a range of different CST loadings and a bed with conduction heat transfer only is about 12 to $13^{\circ} \mathrm{C}$ higher than previous cases with convection heat transfer. This indicates that the conduction-controlled bed provides a conservative estimate of the maximum temperature. These results are consistent with the previous analysis results [2]. It should be emphasized that when the column contains the upper bounding loading of $600 \mathrm{Ci} /$ liter under these conditions that even the calculated bulk-averaged bed temperature exceeds the salt solution boiling point (120 
$\left.{ }^{\circ} \mathrm{C}\right)$. Cases were also run for the mixed bed containing NAS and CST with conductioncontrolled heat transfer within in the bed. As shown in Table 9, the calculation results show that for the NAS/CST mixture the maximum column temperature increases by about $6{ }^{\circ} \mathrm{C}$, while the average plenum temperature did not change.

As discussed earlier, the previous work [8] used the upper limit bed porosity of $50 \%$ for the conservative evaluations of cesium adsorption into CST media. Sensitivity calculations for the two different bed porosities were performed assuming that the solution inside the packed bed was frozen and without considering the natural convection cooling mechanism within the bed. The calculation results are summarized in Table 10. The results show that when the bed porosity changes from the nominal porosity of $43.2 \%$ to the upper bounding value of $50 \%$, the maximum bed temperature decreases by about $3{ }^{\circ} \mathrm{C}$. 

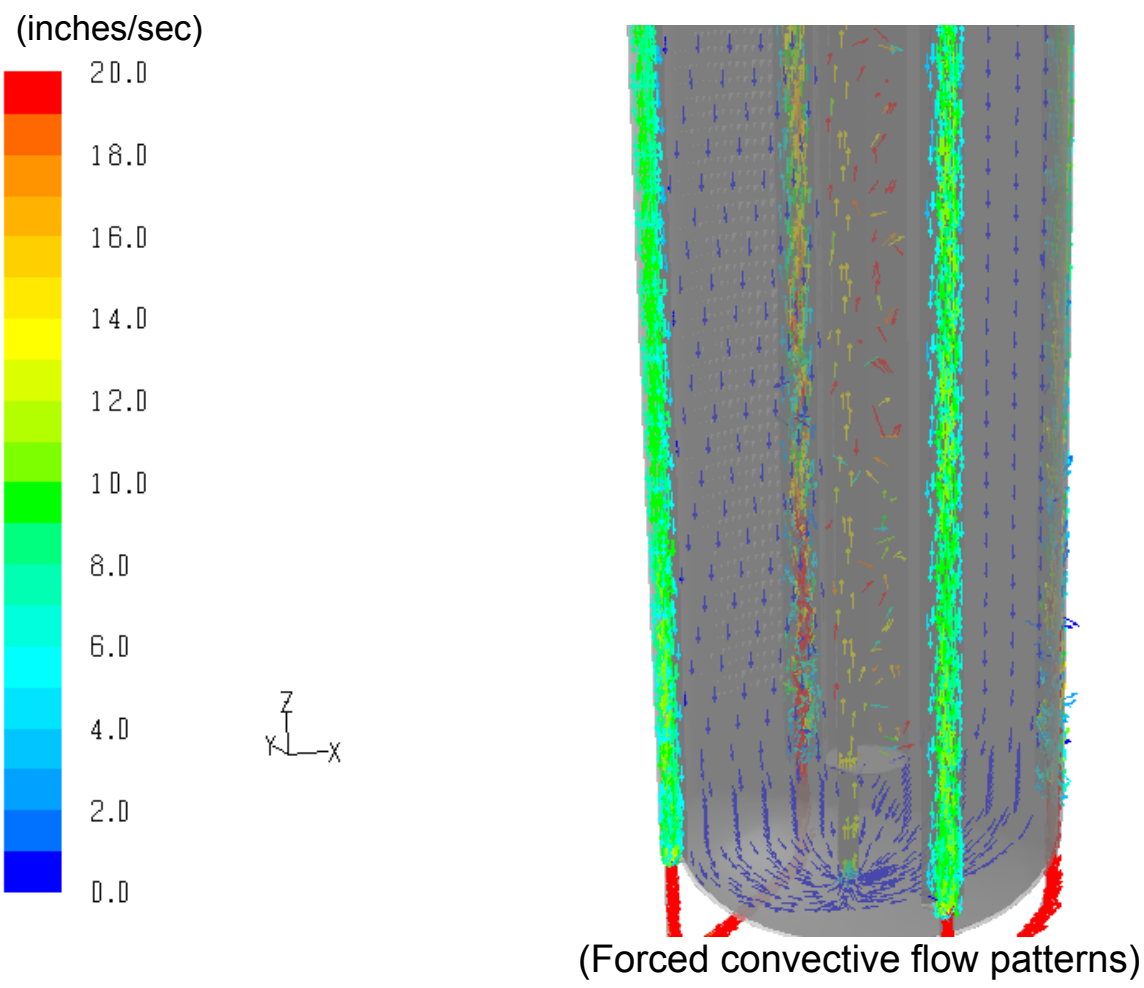

$\left({ }^{\circ} \mathrm{C}\right)$

38.1

37.8

37.5

37.2

36.9

36.5

36.2

35.9

35.6

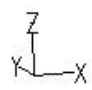

35.3

35.0

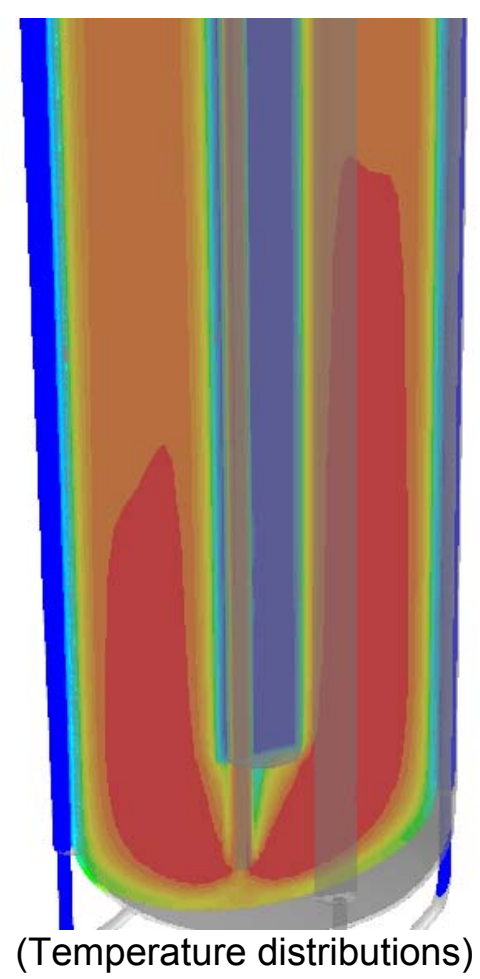

Figure 12. Flow patterns and temperature distributions for the vertical center plane of the SCIX CST bed during the normal operating conditions with $488.8 \mathrm{Ci} /$ liter thermal loading with $5 \mathrm{gpm}$ supernate flow and active cooling. 


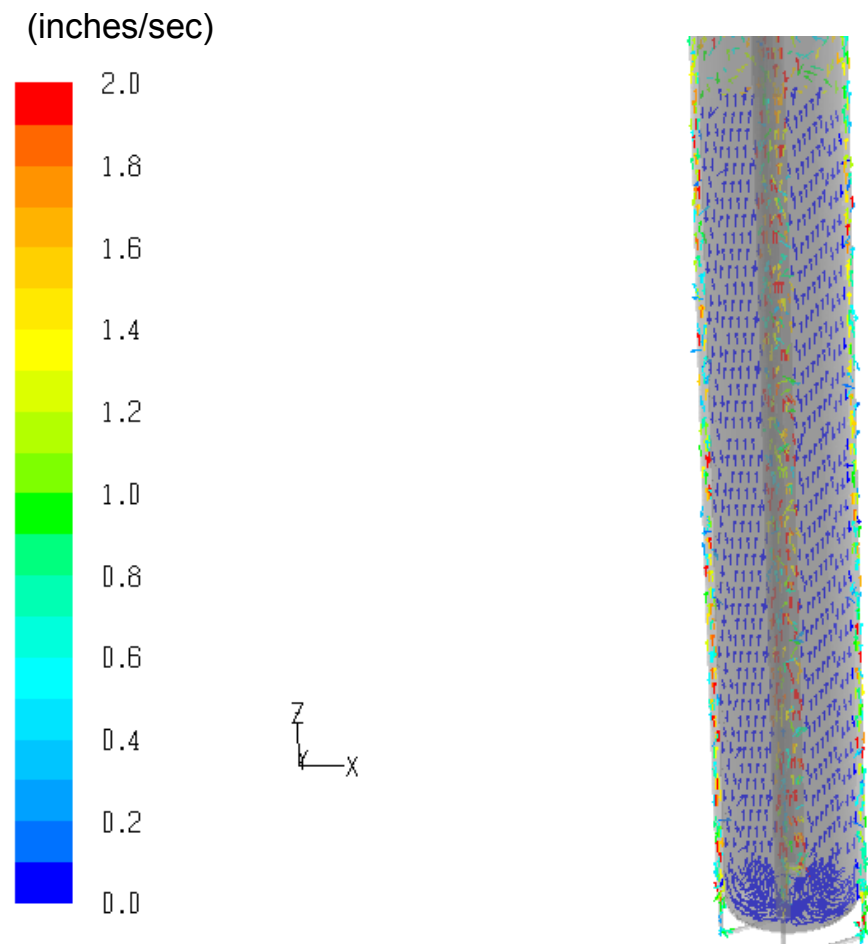

(Natural convective flow patterns driven by buoyancy effect)

$\left({ }^{\circ} \mathrm{C}\right)$

129.3

119.9

110.4

101.0

91.6

82.1

72.7

63.3

53.9

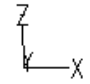

44.4

35.0

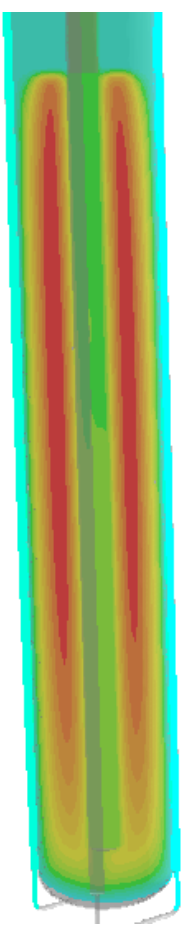

(Temperature distributions during natural convective bed cooling)

Figure 13. Natural convective flow patterns and temperature distributions for the vertical center plane of the SCIX CST bed region with no active cooling and no salt solution flow and $488.8 \mathrm{Ci} /$ liter thermal loading (convective heat transfer allowed in bed). 


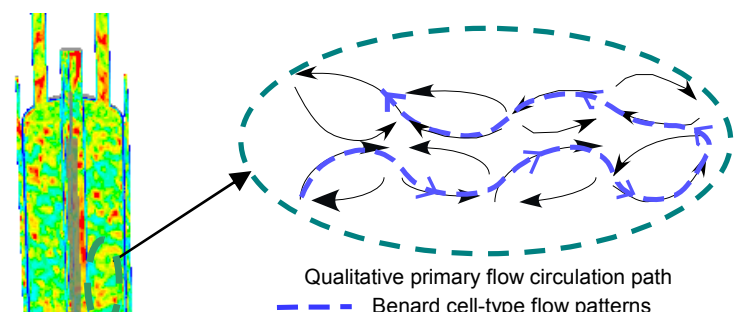

1.200

Figure 14. Natural convective flow distributions for the center plane of the SCIX column (488.8 Ci/liter, $35^{\circ} \mathrm{C}$ ambient temperature, convective heat transfer in bed).

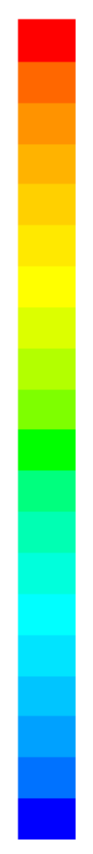

129.6

120.2

110.7

101.2

91.8

82.3

72.9

63.4

53.9

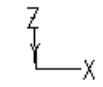

44.5

35.0

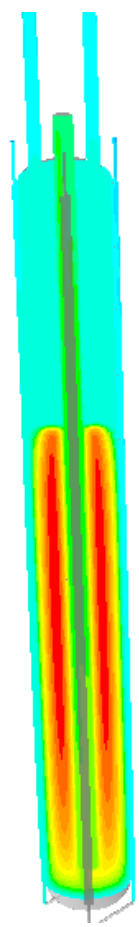

Figure 15. Temperature distributions for the center plane of the SCIX column ( $488.8 \mathrm{Ci} /$ liter, $35^{\circ} \mathrm{C}$ ambient temperature, convective heat transfer in bed). 

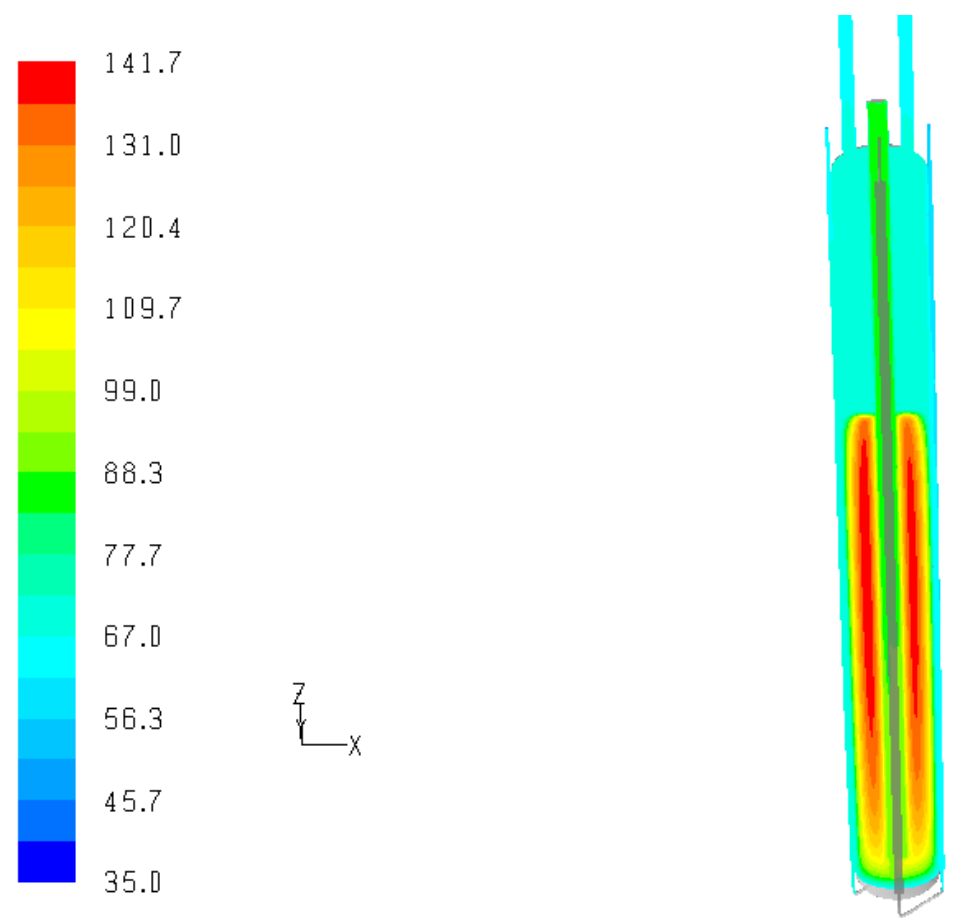

Figure 16. Temperature distributions for the middle plane of the SCIX column ( $554.5 \mathrm{Ci} /$ liter, $35^{\circ} \mathrm{C}$ ambient temperature, convective heat transfer in bed).

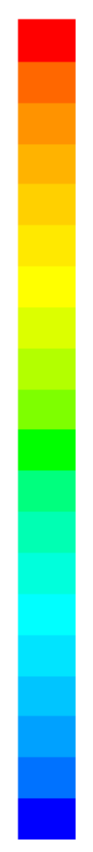

149.7

138.3

126.8

115.3

103.8

92.4

80.9

69.4

$57.9 \quad \frac{7}{k} x$

46.5

35.0

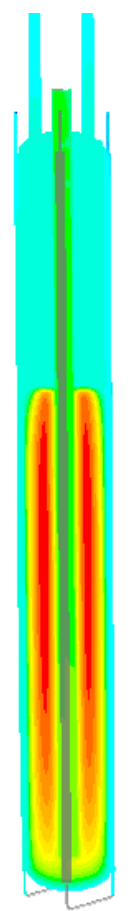

Figure 17. Temperature distributions for the middle plane of the SCIX column $(600 \mathrm{Ci} /$ liter, $35^{\circ} \mathrm{C}$ ambient temperature, convective heat transfer in bed). 
Table 7. Comparison of the modeling predictions and theoretical lumped results for the baseline and bounding loading cases $\left(35^{\circ} \mathrm{C}\right.$ inlet and ambient temperatures)

\begin{tabular}{|c|c|c|c|c|c|c|}
\hline \multirow[t]{2}{*}{$\begin{array}{c}\text { CST } \\
\text { loading } \\
\text { (Curie/liter) }\end{array}$} & \multirow{2}{*}{$\begin{array}{l}\text { Column } \\
\text { Hydraulic } \\
\text { conditions }\end{array}$} & \multicolumn{2}{|c|}{$\begin{array}{c}\text { Engineered cooling } \\
\text { system }\end{array}$} & \multicolumn{2}{|c|}{$\begin{array}{l}\text { Modeling results for } \\
\text { bed temperature } \\
\left({ }^{\circ} \mathrm{C}\right)\end{array}$} & \multirow{2}{*}{$\begin{array}{c}\text { Theoretical } \\
\text { results based } \\
\text { on adiabatic } \\
\text { lumped }\left({ }^{\circ} \mathrm{C}\right) \\
\text { Vol.- } \\
\text { averaged }\end{array}$} \\
\hline & & $\begin{array}{l}\text { Central } \\
\text { cooling } \\
\text { system }\end{array}$ & $\begin{array}{l}\text { External } \\
\text { cooling } \\
\text { system }\end{array}$ & Max. & $\begin{array}{c}\text { Vol.- } \\
\text { averaged }\end{array}$ & \\
\hline \multirow{2}{*}{$\begin{array}{c}488.8 \\
\text { (Baseline) }\end{array}$} & $5 \mathrm{gpm}$ flow & Active & Active & 38.2 & 37.1 & 37.9 \\
\hline & $\begin{array}{l}\text { Stagnant } \\
\text { (Wet) }\end{array}$ & Inactive & Inactive & 129.4 & 104.5 & NA \\
\hline \multirow{2}{*}{$\begin{array}{c}600 \\
\text { (Bounding) }\end{array}$} & $5 \mathrm{gpm}$ flow & Active & Active & 39.4 & 37.5 & 38.6 \\
\hline & $\begin{array}{l}\text { Stagnant } \\
\text { (Wet) }\end{array}$ & Inactive & Inactive & 149.7 & 118.6 & NA \\
\hline
\end{tabular}

${ }^{*}$ convective heat transfer allowed in bed region for stagnant cases

Table 8. Steady-state temperatures for the bed and upper plenum regions of the SCIX column system with no active cooling and no salt solution flow

\begin{tabular}{|c|c|c|c|c|c|}
\hline \multirow{2}{*}{$\begin{array}{l}\text { Thermal } \\
\text { loadings } \\
\text { (Ci/liter) }\end{array}$} & \multirow{2}{*}{$\begin{array}{c}\text { Ambient } \\
\text { temperature } \\
\left({ }^{\circ} \mathrm{C}\right)\end{array}$} & \multicolumn{2}{|c|}{ Bed temperature $\left({ }^{\circ} \mathrm{C}\right)$} & \multicolumn{2}{|c|}{ Upper plenum temperature } \\
\hline & & Max. & $\begin{array}{c}\text { Bed } \\
\text { vol.-averaged }\end{array}$ & $\begin{array}{l}\text { Max. temp. } \\
\quad\left({ }^{\circ} \mathrm{C}\right)\end{array}$ & $\begin{array}{c}\text { Volume-averaged } \\
\text { temp. }\left({ }^{\circ} \mathrm{C}\right)\end{array}$ \\
\hline 488.8 & 35 & 129.4 & 104.5 & 85.9 & 64.2 \\
\hline 554.5 & 35 & 141.7 & 112.9 & 93.9 & 68.4 \\
\hline 554.5 & 25 & 133.1 & 104.6 & 85.0 & 59.8 \\
\hline 600.0 & 35 & 149.7 & 118.6 & 98.5 & 71.1 \\
\hline $\begin{array}{c}600.0 \\
\text { (NAS } \\
\text { addition) }\end{array}$ & 35 & 157.7 & 122.8 & 104.7 & 73.3 \\
\hline
\end{tabular}

${ }^{*}$ convective heat transfer allowed in bed region 
Table 9. Steady-state temperatures for the bed and upper plenum regions of the SCIX column system with no active cooling and no salt solution flow assuming a conduction-controlled packed bed

\begin{tabular}{|c|c|c|c|c|c|}
\hline \multirow{2}{*}{$\begin{array}{l}\text { Thermal } \\
\text { loadings } \\
\text { (Ci/liter) }\end{array}$} & \multirow{2}{*}{$\begin{array}{c}\text { Ambient } \\
\text { temperature } \\
\left({ }^{\circ} \mathrm{C}\right)\end{array}$} & \multicolumn{2}{|c|}{ Bed temperature* $\left({ }^{\circ} \mathrm{C}\right)$} & \multicolumn{2}{|c|}{ Upper plenum temperature } \\
\hline & & Max. & $\begin{array}{c}\text { Bed } \\
\text { vol.-averaged }\end{array}$ & $\begin{array}{l}\text { Max. temp. } \\
\qquad\left({ }^{\circ} \mathrm{C}\right)\end{array}$ & $\begin{array}{c}\text { Volume-averaged } \\
\text { temp. }\left({ }^{\circ} \mathrm{C}\right)\end{array}$ \\
\hline 488.8 & 35 & 141.2 & 110.2 & 78.1 & 61.5 \\
\hline $\begin{array}{c}488.8 \\
\text { (NAS addition) }\end{array}$ & 35 & 150.7 & 115.8 & 78.1 & 61.5 \\
\hline 554.5 & 35 & 154.8 & 120.3 & 83.4 & 65.1 \\
\hline 554.5 & 25 & 146.8 & 111.8 & 75.1 & 56.0 \\
\hline 600.0 & 35 & 163.3 & 125.3 & 86.5 & 65.5 \\
\hline $\begin{array}{c}600.0 \\
\text { (NAS addition) }\end{array}$ & 35 & 175.3 & 131.5 & 86.5 & 65.5 \\
\hline
\end{tabular}

Note:*Based on the effective thermal conductivity for the bed region, assuming the fluid in porous bed to be conduction media

Table 10. Steady-state bed and upper plenum temperatures of the SCIX column system for two different bed porosities with no active cooling and no salt solution flow assuming a conduction-controlled packed bed

\begin{tabular}{|c|c|c|c|c|c|c|}
\hline \multirow[t]{2}{*}{ Porosity } & \multirow{2}{*}{$\begin{array}{l}\text { Thermal } \\
\text { loadings } \\
\text { (Ci/liter) }\end{array}$} & \multirow{2}{*}{$\begin{array}{c}\text { Ambient } \\
\text { temperature } \\
\left({ }^{\circ} \mathrm{C}\right)\end{array}$} & \multicolumn{2}{|c|}{ Bed temperature ${ }^{*}\left({ }^{\circ} \mathrm{C}\right)$} & \multicolumn{2}{|c|}{$\begin{array}{l}\text { Upper plenum } \\
\text { temperature }\end{array}$} \\
\hline & & & Max. & $\begin{array}{c}\text { Bed } \\
\text { vol.-averaged }\end{array}$ & $\begin{array}{l}\text { Max. temp. } \\
\quad\left({ }^{\circ} \mathrm{C}\right)\end{array}$ & $\begin{array}{c}\text { Vol.-averaged } \\
\text { temp. }\left({ }^{\circ} \mathrm{C}\right)\end{array}$ \\
\hline $\begin{array}{c}0.432 \\
\text { (Nominal) }\end{array}$ & 600.0 & 35 & 163.3 & 125.3 & 86.5 & 65.5 \\
\hline 0.5 & 600.0 & 35 & 160.7 & 123.7 & 86.7 & 65.7 \\
\hline $\begin{array}{c}0.432 \\
\text { (Nominal) }\end{array}$ & $\begin{array}{c}600.0 \\
\text { (NAS addition) }\end{array}$ & 35 & 175.3 & 131.5 & 86.5 & 65.5 \\
\hline 0.5 & $\begin{array}{c}600.0 \\
\text { (NAS addition) }\end{array}$ & 35 & 171.1 & 129.5 & 87.0 & 66.0 \\
\hline
\end{tabular}

Note:*Based on the effective thermal conductivity for the bed region, assuming the fluid in porous bed to be conduction media 


\subsection{IN-TANK THERMAL MODELING RESULTS}

For the in-tank evaluations, key modeling parameters changed based on the previous results [2]. The previous modeling efforts involved a tank floor with heat transfer into the $150 \mathrm{ft}-d e e p$ soil region and unground CST media with a nominal loading of $257 \mathrm{Ci} / \mathrm{L}$. The present modeling calculations were conducted to ensure conservative predictions for the maximum temperatures achievable using the current baseline design. However, the degree of conservatism was reduced relative to previous calculations by the selection of parameters which were nearer to expected conditions. For the extended thermal modeling effort, a 20ft-deep soil region [24] was used to determine the maximum floor temperatures within the tank loaded with ground spent CST. The current in-tank evaluations also incorporated recently updated maximum cesium loading levels calculated using the current SCIX feed compositions which resulted in significantly higher cesium loading than previously calculated [8].

For the in-tank thermal modeling analysis, a ground CST mound with $100 \%$ cesium loading with active cooling through the cooling tubes inside of Tank 41 was considered to be the baseline condition. In all cases, forced convection mixing effects that would be expected as a result of operation of the submersible jet mixer pumps in the tank were assumed to be negligible. The external wall surfaces of the 85- $\mathrm{ft}$ diameter tank boundary were cooled by natural convection coupled with radiation, neglecting air ventilation effects around the tank. A constant ambient temperature of $35{ }^{\circ} \mathrm{C}$ was assumed. Calculations involved the determination of steady-state temperatures.

Figure 18 shows the temperature distributions for the two initial cases for the in-tank model involving 150 and $20 \mathrm{ft}$ deep soil regions when a 9-in cylindrical layer of ground CST media which corresponds to a mound volume of 675 gallons is located on the tank floor. Both cases were based on an equilibrium soil temperature of $20{ }^{\circ} \mathrm{C}$ at the bottom of the soil penetration region and a cesium loading of $514 \mathrm{Ci} / \mathrm{L}$ (equivalent to $257.2 \mathrm{Ci} / \mathrm{L}$ unground basis). The maximum tank wall temperature was found to be insensitive to the depth of soil region as shown in Fig. 18. As shown in Table 11, the maximum tank wall temperature for the $20 \mathrm{ft}$ deep soil case is less than $1{ }^{\circ} \mathrm{C}$ higher than predicted for the $150 \mathrm{ft}$ deep case. These results indicate that reducing the soil penetration depth from 150 to 20 feet did not significantly affect the model predictions. For all subsequent intank modeling cases a 20 foot soil penetration depth was used.

Figure 19 shows velocity flow patterns and temperature distributions for the vertical middle plane crossing the center of a 225 gallon cylindrical, ground CST mound with a 3 inch height when the mound is thermally loaded with $1200 \mathrm{Ci} /$ liter (bounding loading for ground CST). This ground CST volume is believed to be representative of one SCIX processing cycle. In this case, the maximum tank wall temperature reaches about $69^{\circ} \mathrm{C}$ and the maximum CST mound temperature reaches about $71^{\circ} \mathrm{C}$. The figure also shows that the maximum upward fluid velocity driven by buoyancy effects reaches about 0.7 inches/sec. The sensitivity of the maximum tank wall temperature to the thermal loading was evaluated for this mound volume. Figure 20 compares the temperature distributions for three different thermal loadings of 978,1109 , and $1200 \mathrm{Ci} /$ liter (correspond to 489, 554.5 , and $600 \mathrm{Ci} / \mathrm{L}$, respectively, for the unground material) along the vertical line A-A' crossing the center of the 225 gallon ground CST mound. The results show that the maximum tank wall temperature increases by about $10 \%\left(63{ }^{\circ} \mathrm{C}\right.$ to $\left.69^{\circ} \mathrm{C}\right)$ when thermal loading of the 3 -in mound increases by $23 \%$ from the nominal value of $978 \mathrm{Ci} /$ liter. Figure 21 compares the calculated temperature distributions for 3 and 6 inch mounds corresponding to the volumes of 225 and 450 gallons (37 inch radius) for the bounding loading. The results show that when the cylindrical height of the mound doubles (from 3 
to 6 inches), the maximum tank wall temperature increases by about $77 \%$. Figure 22 presents the maximum tank floor temperatures as a function of the cylindrical CST mound height for the nominal and bounding loading values. The results show that when the mound height is kept less than 5 inches, the maximum tank wall temperature remains below $100{ }^{\circ} \mathrm{C}$ for a loading of $1200 \mathrm{Ci} /$ liter. A quantitative comparison of the maximum tank wall temperatures for three different heights of cylindrical ground CST mounds under different thermal loadings is provided in Table 12. Cylindrical shapes with different aspect ratios were evaluated in the previous work [2]. The results clearly indicate that the wall temperature is very sensitive to the cylindrical mound height and not highly sensitive to the loading level (at least in the nominal to bounding range).

Table 13 shows the results for ground CST mound volumes differing by over nearly an order of magnitude (225 versus 2100 gallons) with a 3-in height loaded with $1200 \mathrm{Ci} /$ liter. As shown in the table, maximum tank wall temperature increases by only about $30 \%$ and remains below $100{ }^{\circ} \mathrm{C}$ even though the mound volume increased by a factor of 9.3 . Comparison of the maximum steady-state wall temperatures observed for the two different cylindrical volumes of ground CST mound is provided graphically in Figure 23. The results reveal that the tank wall temperature is not sensitive to this large volume change because the 32,000 gallons of liquid in the tank and $20-\mathrm{ft}$ soil region below the tank serve as a large heat sink for the CST heat load. The comparison for two mounds with dramatically different volumes (225 and 2100 gallons) reveals that heat transfer from the mound is primarily vertical for high aspect ratio mound geometries. As a result, the maximum wall temperatures are primarily determined by the mound height, with minimal impacts from the mound width and total volume. This in-tank modeling result emphasizes the importance of distributing the CST on the tank floor with minimal mounds or piles of material.

Also provided in Table 13 are the in-tank modeling results for NAS/CST mixture (16 wt $\%$ NAS). In this case, the maximum tank wall temperature increases by about $1{ }^{\circ} \mathrm{C}$ due to the presence of the NAS within the mound. As shown in Table 14, when the bed porosity was increased from the nominal value of $43.2 \%$ to the upper bound limit of $50 \%$, the maximum tank wall temperature decreased by only about $0.5^{\circ} \mathrm{C}$.

The cooling coils immersed in the liquid serve as the primary heat transfer mechanism for the system. However, significant heat transfer occurs through the tank floor. As shown in Fig. 24, removing heat transfer through the floor results in dramatic increases in the maximum wall temperatures. It is also noted that when the heat transfer across the tank bottom is considered, the location of the maximum temperature within the mound changes from near the bottom of the mound to the center of the mound. These results indicate that more than one third of the total thermal loading generated by the spent CST materials accumulated on the tank floor is dissipated through the tank bottom. 

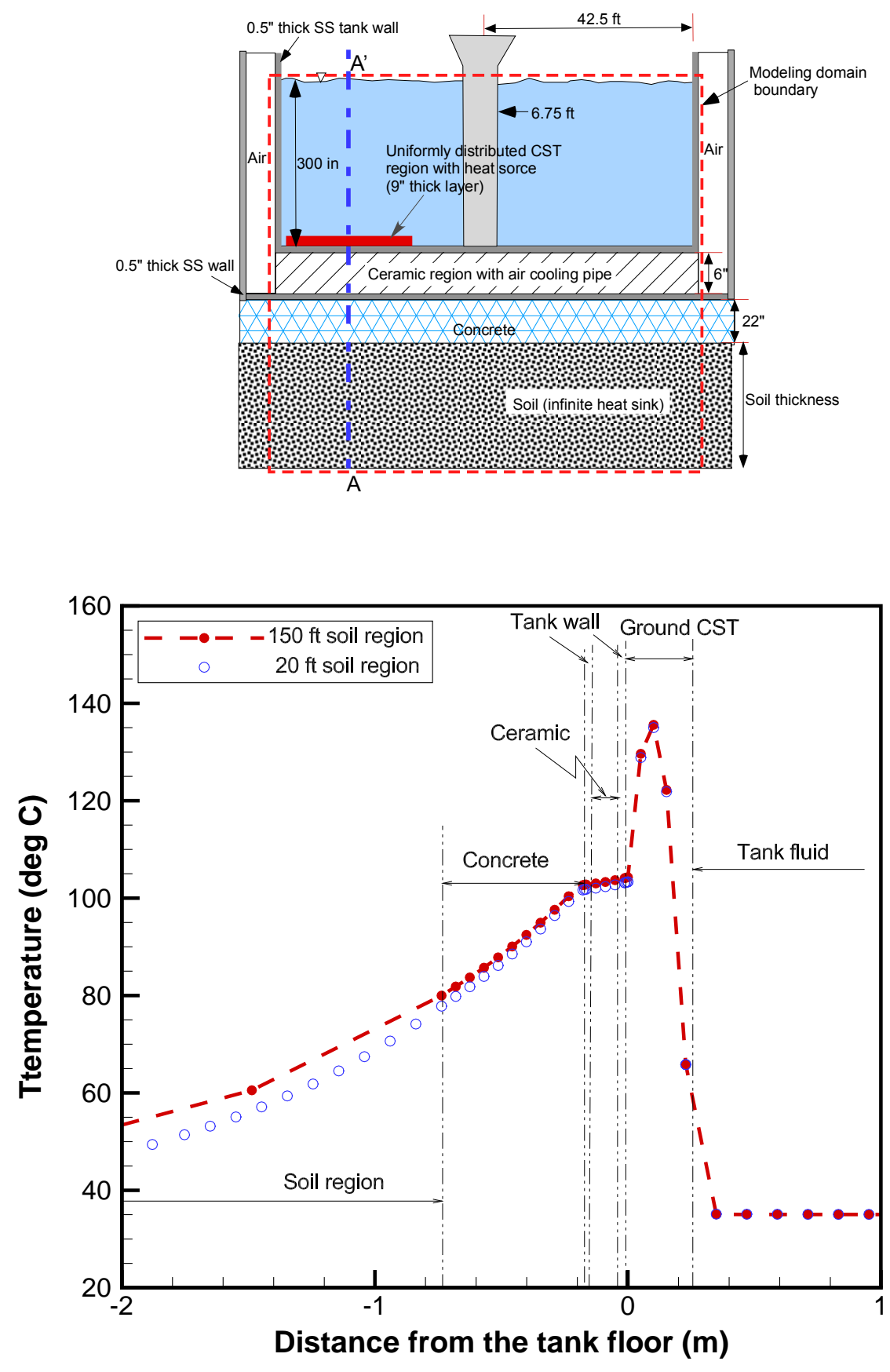

Figure 18. Comparison of temperature distributions along the line A-A' between the two different soil depths under a 9 in thick ground CST mound of 675 gallons 
Table 11. Quantitative comparison of maximum tank floor temperatures for two different soil boundaries under a 9 in cylindrical ground CST mound

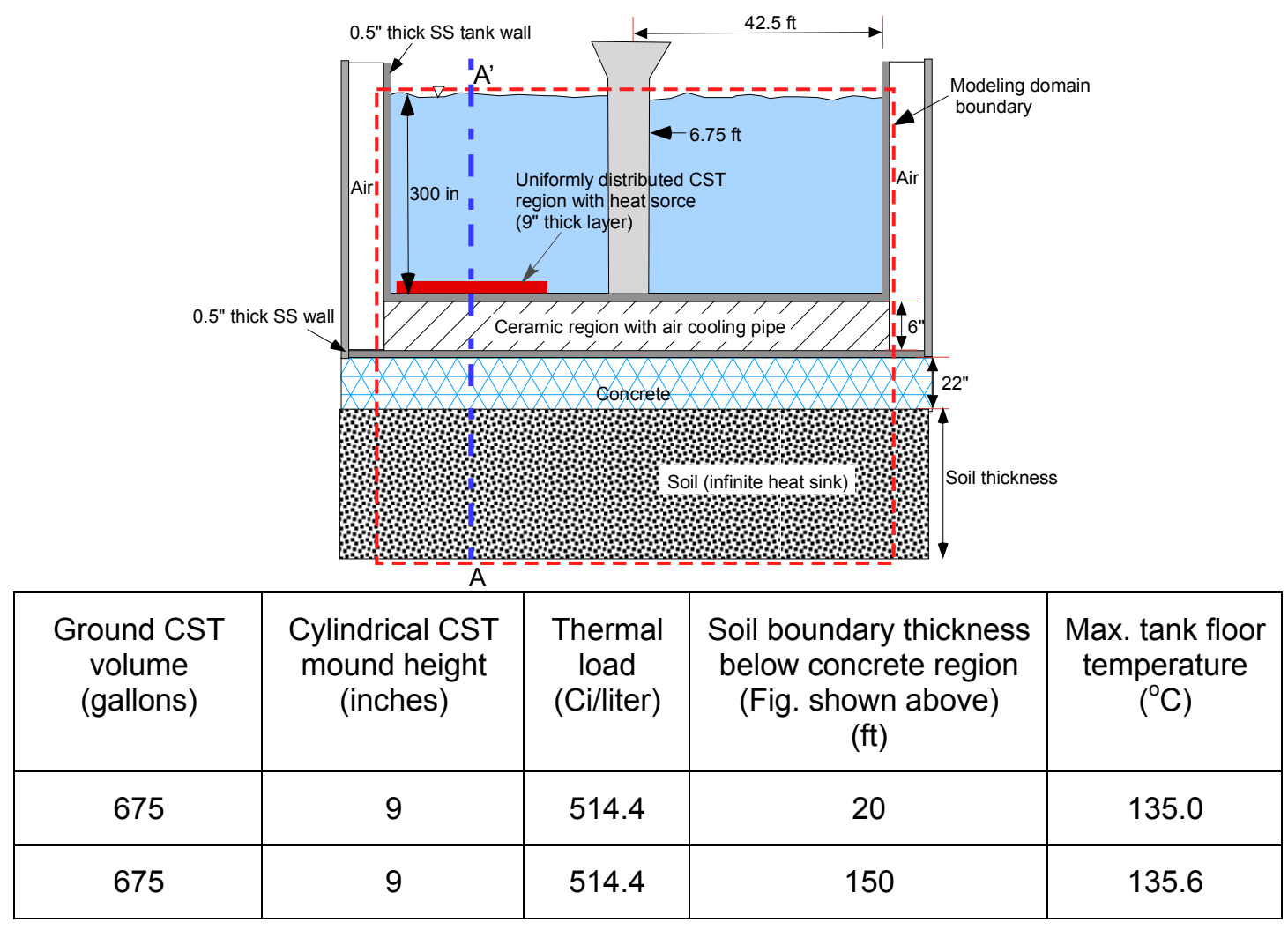




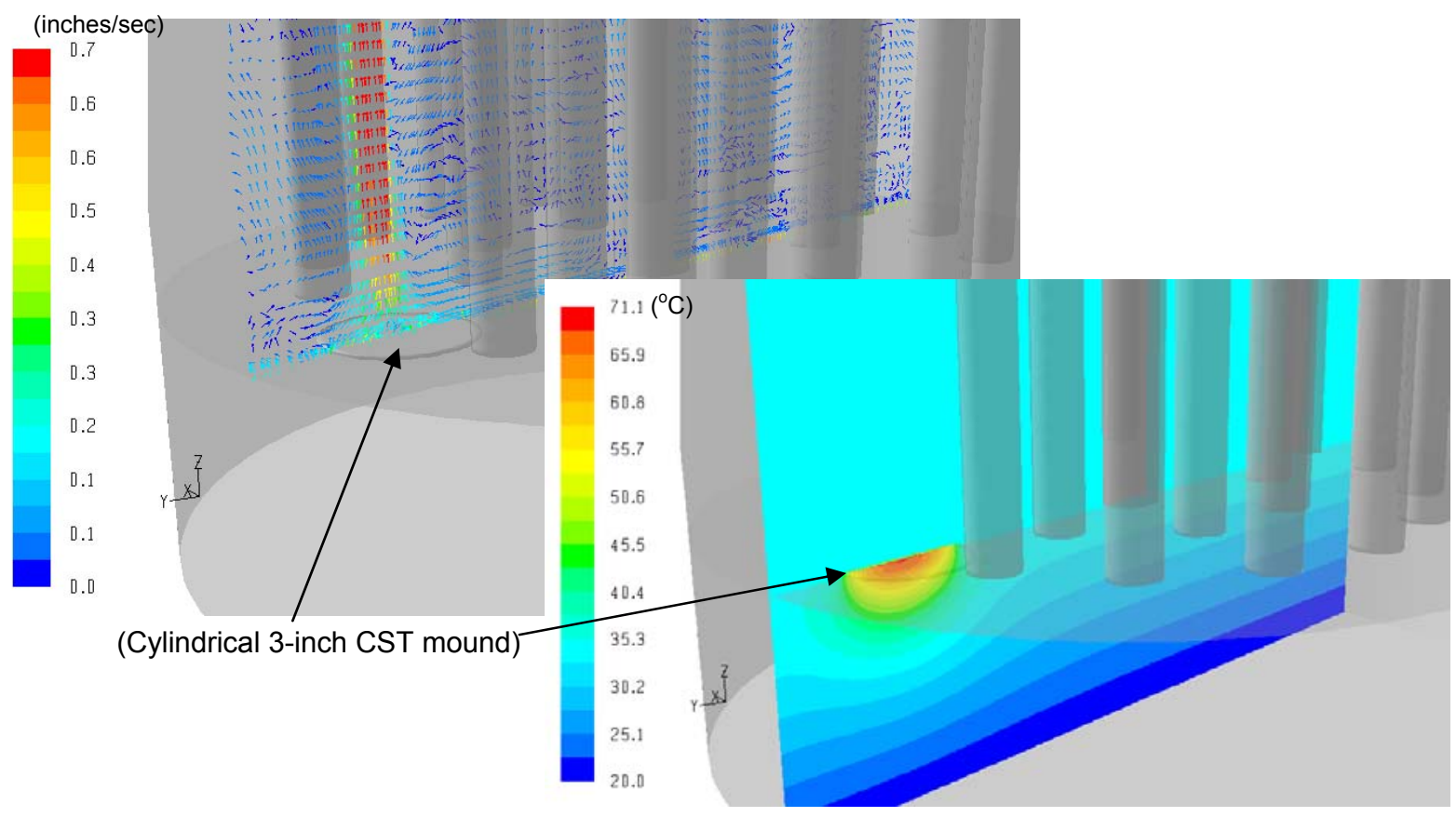

Figure 19. Velocity flow patterns and temperature distributions for the vertical middle plane crossing the center of the 225 gallon cylindrical ground CST mound with 3 in height (1200 Ci/liter) 

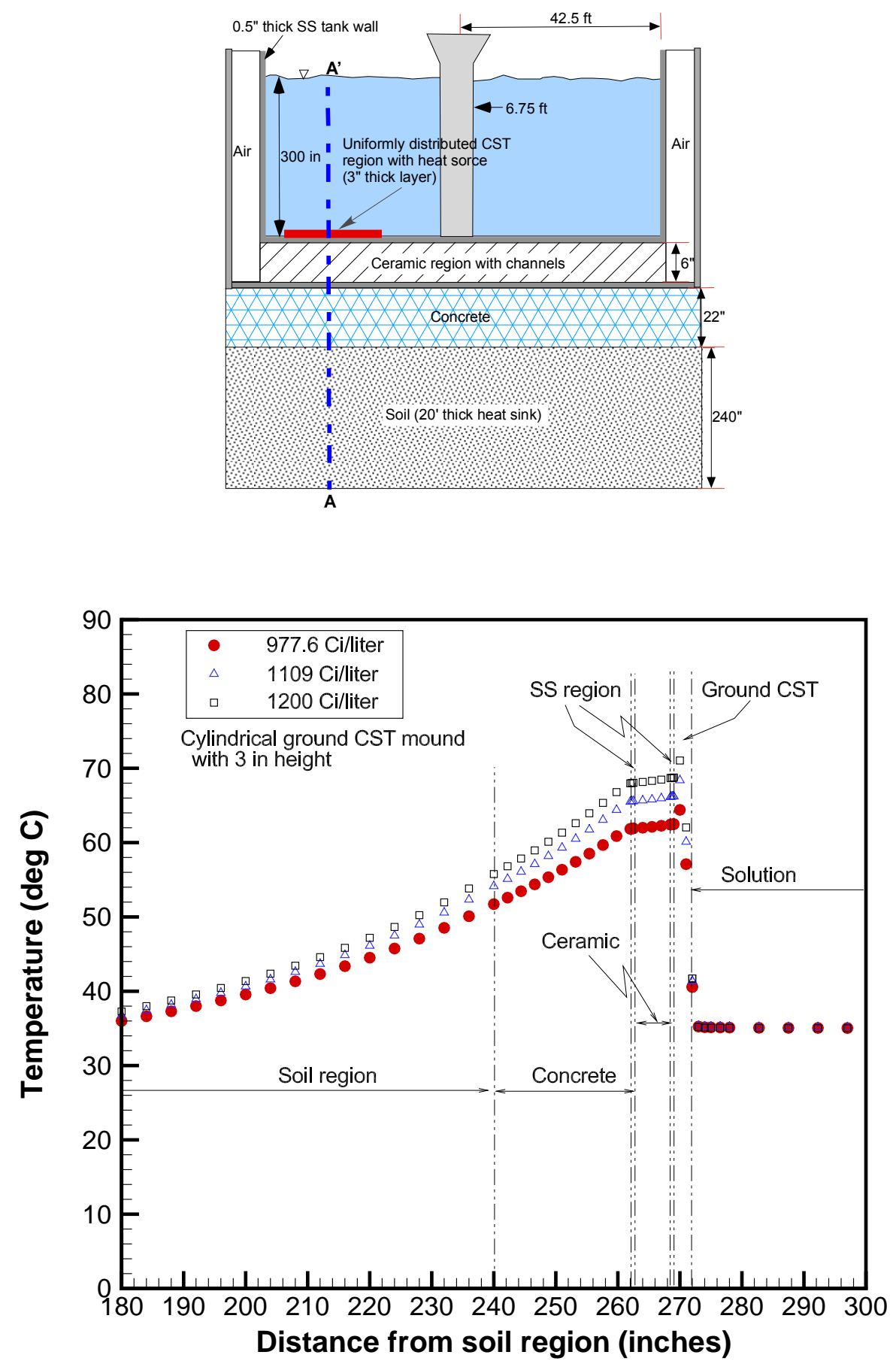

Figure 20. Comparison of temperature distributions for three different thermal loadings along the vertical line A-A' crossing the center of the 225 gallon ground cylindrical CST mound with 3 in height 

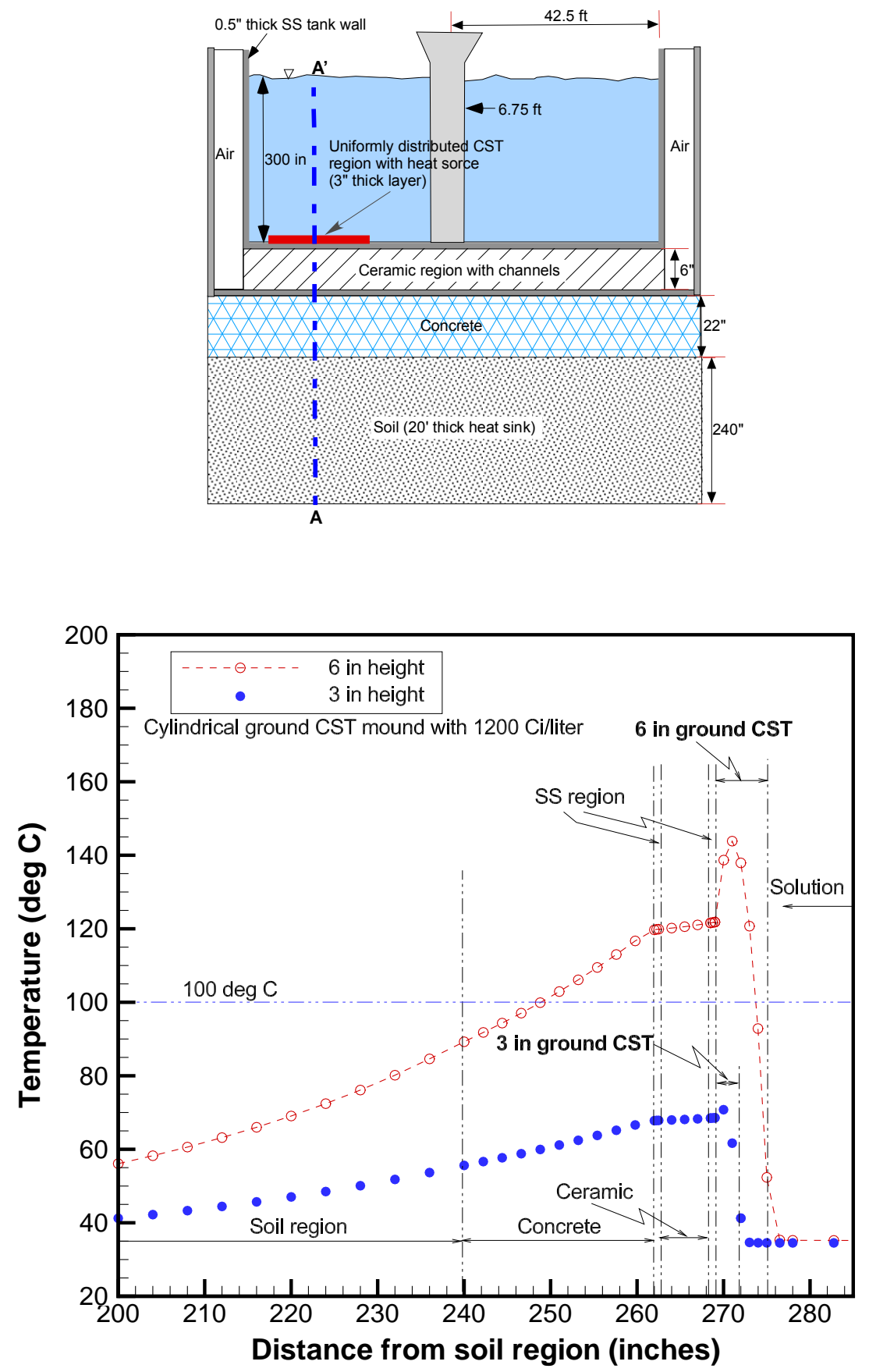

Figure 21. Comparison of temperature distributions along the vertical line A-A' between the two different cylindrical ground CST mound heights with 37 in radius corresponding to the volumes of 225 and 450 gallons 


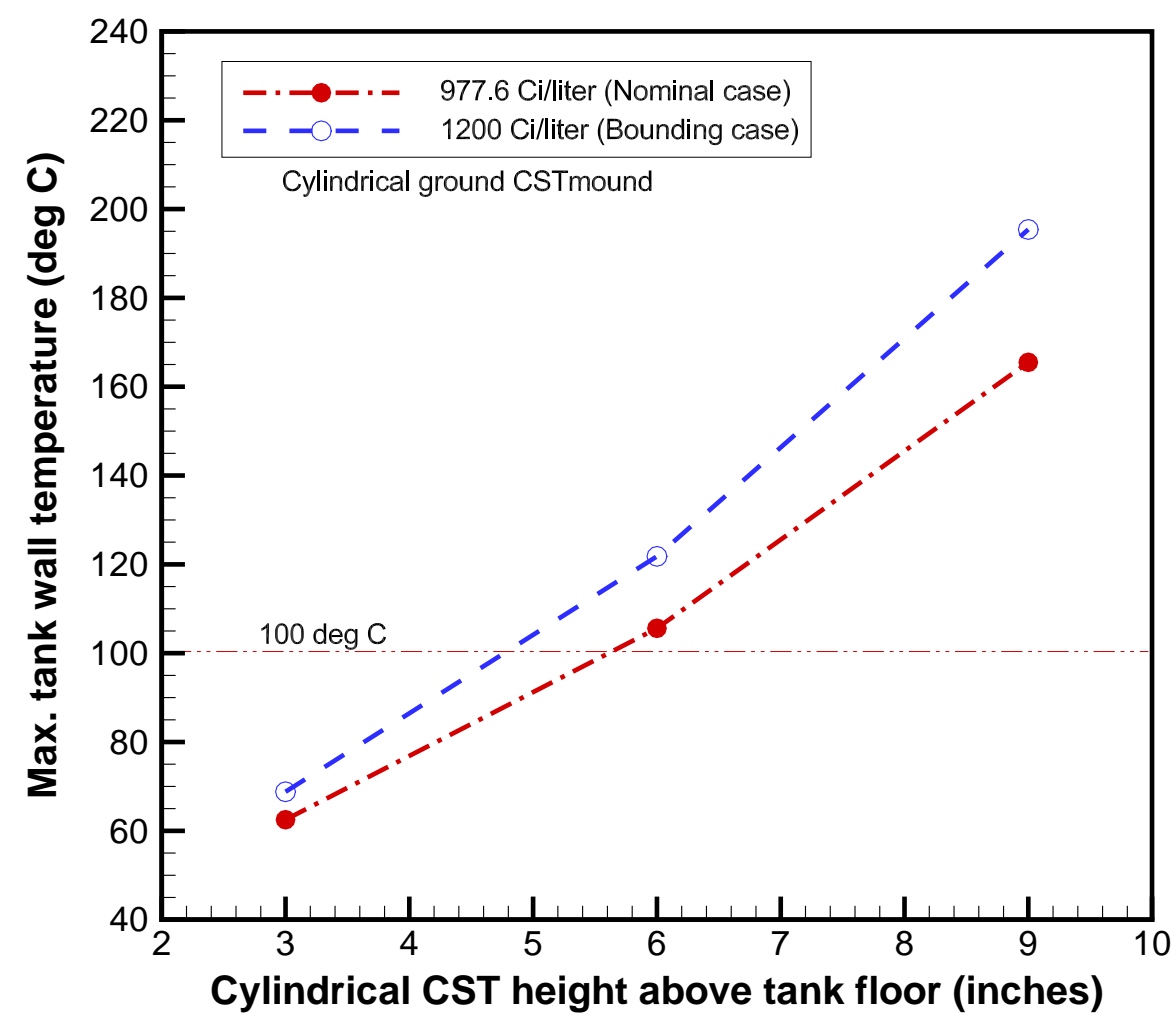

Figure 22. Maximum tank floor temperature versus mound height for the nominal and bounding CST loading levels

Table 12. Maximum tank wall temperatures for three different heights of cylindrical ground CST mounds as function of thermal loadings (Ambient temperature $=$ $\left.35^{\circ} \mathrm{C}\right)$

\begin{tabular}{|c|c|c|c|c|}
\hline \multicolumn{2}{|c|}{ Thermal loading for ground CST } & \multicolumn{3}{|c|}{$\begin{array}{c}\text { Max. tank wall temp. for cylindrical ground CST } \\
\text { mound heights }\left({ }^{\circ} \mathrm{C}\right)\end{array}$} \\
\hline Ci/liter & $\begin{array}{c}\text { Watts/ } \\
\mathrm{m}^{3}\end{array}$ & $\begin{array}{l}3 \text { inches } \\
\text { (225 gal) }\end{array}$ & $\begin{array}{l}6 \text { inches } \\
\text { (450 gal) }\end{array}$ & $\begin{array}{l}9 \text { inches }(675 \\
\text { gal) }\end{array}$ \\
\hline $\begin{array}{c}977.6 \\
\text { (Nominal case) }\end{array}$ & 4839.2 & 62.5 & 105.7 & 165.5 \\
\hline $\begin{array}{c}1109.0 \\
\text { (Max. loading) }\end{array}$ & 5489.6 & 66.2 & 115.2 & 183.2 \\
\hline $\begin{array}{c}1200.0 \\
\text { (Bound Case) }\end{array}$ & 5940.0 & 68.8 & 121.9 & 195.4 \\
\hline
\end{tabular}


Table 13. Maximum tank wall temperatures for different bed volumes of 3-in cylindrical ground CST mounds with and without NAS addition

\begin{tabular}{|c|c|c|c|c|}
\hline \multirow{2}{*}{$\begin{array}{c}\text { Volume of 3-in height } \\
\text { ground CST mound } \\
\text { (gallons) }\end{array}$} & \multicolumn{2}{|c|}{ Thermal loadings } & $\begin{array}{c}\text { Ambient } \\
\text { temperature } \\
\left({ }^{\circ} \mathrm{C}\right)\end{array}$ & $\begin{array}{c}\text { Max. tank wall } \\
\text { temperature } \\
\left({ }^{\circ} \mathrm{C}\right)\end{array}$ \\
\cline { 2 - 4 } & (Ci/liter) & $\left(\right.$ watts $\left./ \mathrm{m}^{3}\right)$ & 35 & 68.8 \\
\hline 225 & 1200 & 5940 & 35 & 70.1 \\
\hline $\begin{array}{c}225 \\
\text { (NAS added) }\end{array}$ & 1200 & 5940 & 35 & 90.1 \\
\hline 2100 & 1200 & 5940 & 35 & \\
\hline
\end{tabular}

Table 14. Maximum tank wall temperatures for different bed porosities of 3-in cylindrical ground CST mounds with and without NAS addition

\begin{tabular}{|c|c|c|c|c|c|}
\hline $\begin{array}{c}\text { Bed porosity } \\
\text { with original } \\
\text { unground } \\
\text { CST }\end{array}$ & $\begin{array}{c}\text { Vol. of 3-in } \\
\text { height ground } \\
\text { CST mound } \\
\text { (gallons) }\end{array}$ & \multicolumn{2}{|c|}{ Thermal loadings } & $\begin{array}{c}\text { Ambient } \\
\text { temperature } \\
\left({ }^{\circ} \mathrm{C}\right)\end{array}$ & $\begin{array}{c}\text { Max. tank } \\
\text { wall } \\
\text { temperature } \\
\left({ }^{\circ} \mathrm{C}\right)\end{array}$ \\
\cline { 3 - 6 } $\begin{array}{c}0.432 \\
\text { (Nominal) }\end{array}$ & 225 & 1200 & 5940 & 35 & 68.8 \\
\hline 0.50 & 225 & 1200 & 5940 & 35 & 68.3 \\
\hline $\begin{array}{c}0.432 \\
\text { (Nominal) }\end{array}$ & $\begin{array}{c}225 \\
\text { (NAS added) }\end{array}$ & 1200 & 5940 & 35 & 70.1 \\
\hline 0.50 & $\begin{array}{c}225 \\
\text { (NAS added) }\end{array}$ & 1200 & 5940 & 35 & 69.8 \\
\hline
\end{tabular}



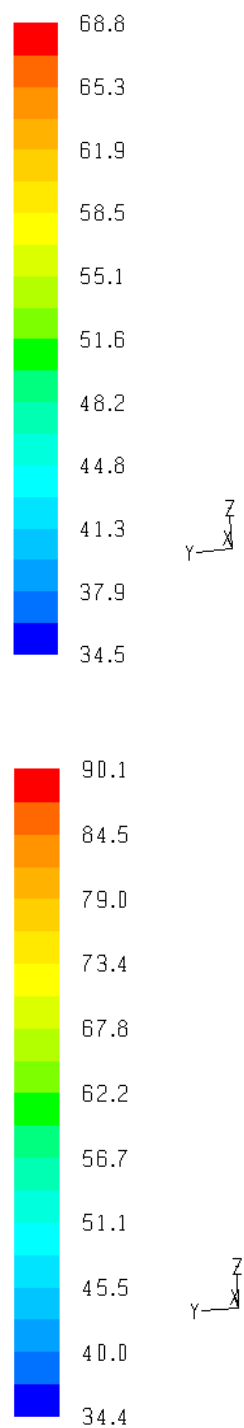

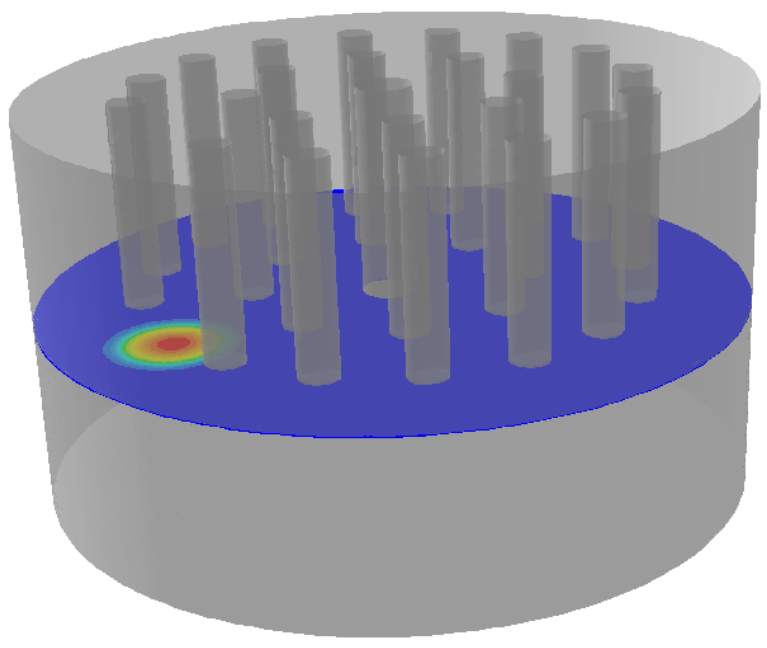

(225 gal ground CST mound with 3 in height)

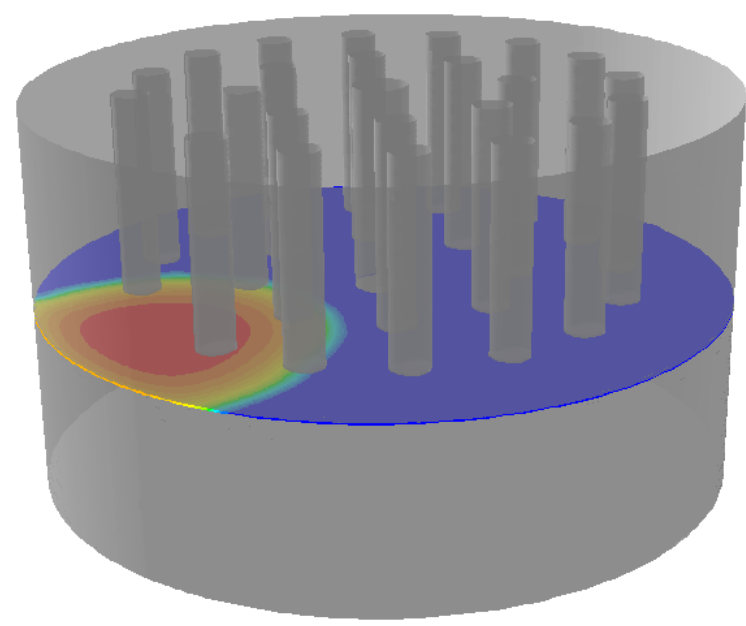

(2100 gal ground CST mound with 3 in height)

Figure 23. Comparison of steady-state tank floor temperature distributions for two different volumes of ground CST mound with a 3 in height (1200 Ci/liter) 

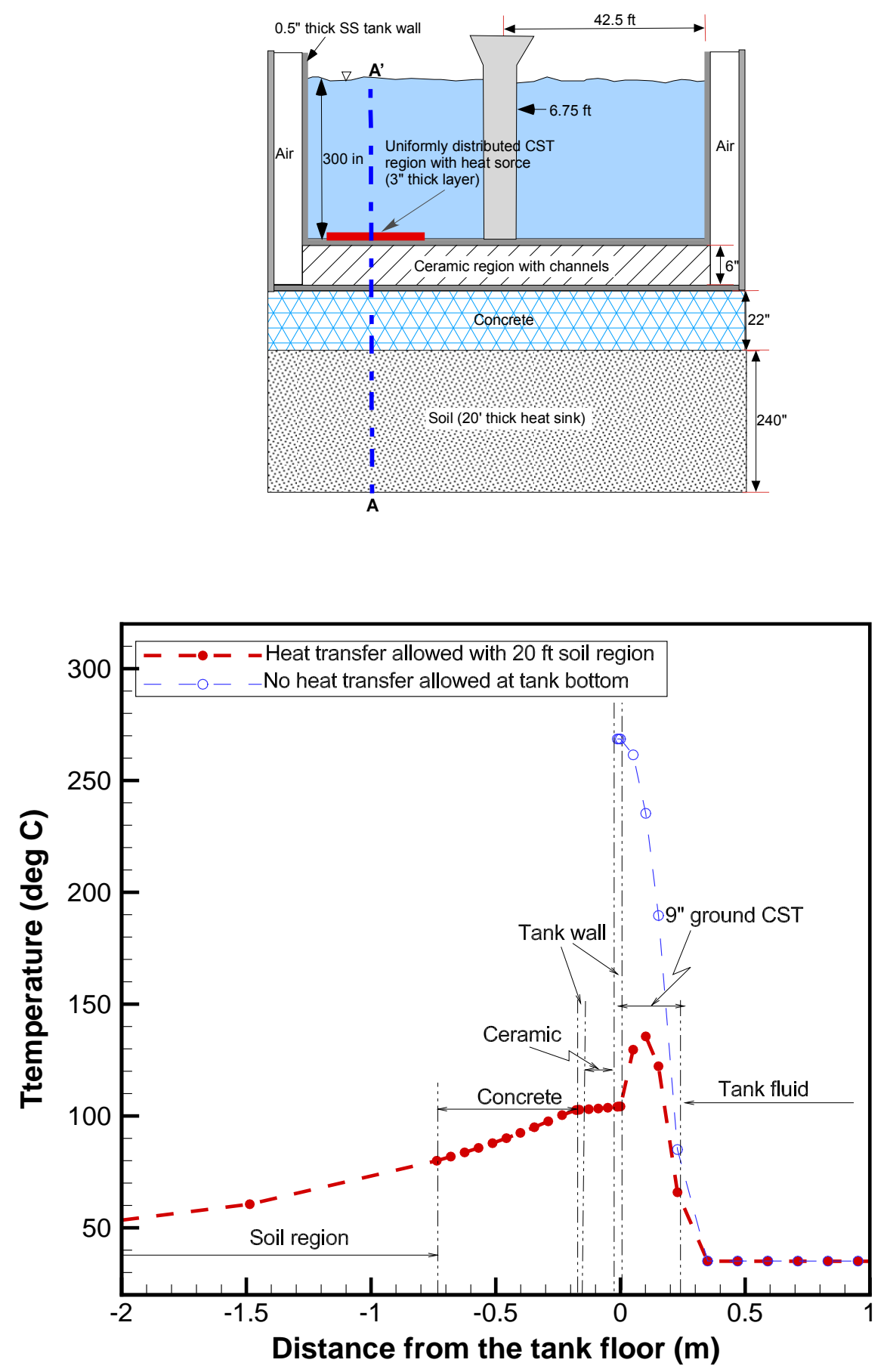

Figure 24. Comparison of steady-state temperature distributions along the vertical line A-A' between the 9-in ground CST model with and without heat transfer at the bottom of tank (Ground CST mound loaded with $514.4 \mathrm{Ci} /$ liter) 


\subsection{CONCLUSIONS}

The main results are summarized as follows:

- With the bounding cesium loading $(600 \mathrm{Ci} / \mathrm{L}), 5 \mathrm{gpm}$ supernate flow through the column, and with active engineered cooling the maximum column temperature should be below $40{ }^{\circ} \mathrm{C}$.

- For a CST column filled with stagnant supernate and with inactive engineered cooling and $35^{\circ} \mathrm{C}$ ambient external air, the peak localized temperature for the column loaded with $488.8 \mathrm{Ci} /$ liter nominal loading is about $129^{\circ} \mathrm{C}$, which is above the supernate boiling point. The volume-averaged temperature of $105^{\circ} \mathrm{C}$ is below the boiling point. The maximum temperature for the upper plenum region is only $86^{\circ} \mathrm{C}$.

- When the porous bed is treated as a conduction-controlled media, the calculated peak localized temperature of the naturally-cooled (no active cooling) column filled with stagnant supernate in the upper plenum is about $163^{\circ} \mathrm{C}$ for the nominal loading case. The volume-averaged temperature for the conduction-controlled bed is 125 ${ }^{\circ} \mathrm{C}$, but the maximum upper plenum temperature is only $87^{\circ} \mathrm{C}$.

- With 16 wt\% sodium aluminosilicate fouling of the CST bed and assuming no convective heat transfer in the bed, the maximum bed temperature was predicted to be $173^{\circ} \mathrm{C}$ for the bounding loading case $(600 \mathrm{Ci} /$ liter $)$ with a volume-averaged bed temperature of $132{ }^{\circ} \mathrm{C}$, which is over the salt solution boiling point. However, the maximum temperature of the plenum in this case was only $87^{\circ} \mathrm{C}$. Therefore, bulk boiling within the column is not expected even in this worst case condition.

- Evaluations of cylindrical CST mounds in the waste tank with high aspect ratios revealed that the mound height (rather than the width or volume) is the primary factor influencing the maximum floor temperature. This indicates that for this mound geometry the heat transfer pathway is primarily vertical.

- For cylindrical mounds of ground CST in the tank with heights of $\leq 5$ inches, the maximum floor temperature is maintained below $100{ }^{\circ} \mathrm{C}$. The results indicate that regardless of the total CST volume, floor temperature limits will not be exceeded as long as no piles of CST are present with a height exceeding 5 inches. Based on these results, in-tank mixing of the spent CST is required.

- The in-tank modeling results show that when $16 \mathrm{wt} \%$ NAS material is accumulated on the CST, the maximum tank wall temperature increases by about $1^{\circ} \mathrm{C}$. 


\subsection{REFERENCES}

1. S. Y. Lee and W. D. King, "Task Technical and Quality Assurance Plan for Extended Thermal Modeling of the SCIX CST Column", SRNL-TR-2011-00119, Rev. 0, July 2011.

2. S. Y. Lee and W. D. King, "Thermal Modeling Analysis of CST media in the Small column ion Exchange project”, SRNL-STI-2010-00570, October 2010.

3. S. Ergun, "Fluid Flow Through Packed Columns", Chem. Eng. Progress, vol. 48, No. 2, pp. 89-94, February 1952.

4. W. D. King, F. G. Smith, S. Y. Lee, D. J. McCabe, and T. Punch, "Comparisons of RF and CST Media for Cesium Removal by In-Tank Column Processing", $15^{\text {th }}$ Symposium on Separation Science and Technology, Gatlinburg, TN, October 2007.

5. F. G. Smith, III, S. Y. Lee, W. D. King, D. J. McCabe, "Comparisons of Crystalline Silicotitanate and Resorcinol Formaldehyde Media for Cesium Removal by In-tank Column Processing", Separation Science and Technology, vol. 43, pp. 2929, 2008.

6. C. M. Cole, "CSTF Corrosion Control Program: Program Description Document", WSRC-TR-2003-00327, Rev. 4, December 2007.

7. B. B. Spencer, H. Wang, K. K. Anderson, "Thermal Conductivity of IONSIVIE-911TM Crystalline Silicotitanate and Savannah River Waste Simulant Solutions",ORNL/TM2000/285, Oak Ridge National Laboratory, TN, 2000.

8. F. G. Smith, III, "Modeling CST lon-Exchange for Cesium Removal from SCIX Batches 1 - 4", SRNL-STI-2011-00181 Rev. 0, April 2011.

9. W. M. Kays and M. E. Crawford, Convective Heat and Mass Transfer, Second Edition, McGraw-Hill Book Company, New York (1980).

10. S. Y. Lee, "Three-Dimensional Thermal Performance Analysis for HLW Disposal Gallery", SRNL technical report, WFO-08-014-1, July 27, 2009.

11. S. Y. Lee, "Two-Phase Flow and Heat transfer in Porous Media", MS Thesis, Massachusetts Inst. of Technology, 1983.

12. C. Y. Warner and V. S. Arpaci, "An Experimental Investigation of Turbulent Natural Convection in Air at Low Pressure along a Vertical Heated Flat Plate", International Journal of Heat and Mass Transfer, Vol. 11, pp. 397-406, 1968.

13. S. W. Churchill and H. H. S. Chu, "Correlating Equations for Laminar and Turbulent Free Convection from a Vertical Plate", Int. J. Heat Mass Transfer, vol. 18, pp. 1323, 1975.

14. P. A. Taylor and C. H. Mattus "Thermal and Chemical Stability of Baseline and Improved Crystalline Silicotitanate" ORNL/TM-2001/165, December 2001.

15. Fluent ${ }^{T M}$, ANSYS, Inc., 2008.

16. R. Krupiczka, "Analysis of Thermal Conductivity in Granular Materials", International Chemical Engineering, Vol. 7, No. 1, pp. 122-144 (1967).

17. S. E. Aleman, G. P. Flach, L. L. Hamm, S. Y. Lee, and F. G. Smith, III, 1993, "FLOWTRAN-TF Code Software Design (U)", WSRC-TR-92-532, Savannah River National Laboratory, Westinghouse Savannah River Company, February 1993.

18. V. E. Schrock, C. H. Wang, S. Revankar, L. H. Wei, and S. Y. Lee, "Steam-Water Flooding in Debris Beds and Its Role in Dryout", Electric Power Research Institute, EPRI NP-3858, March 1985.

19. A. B. Yu and N. Standish, "Estimation of the Porosity of Particle Mixtures by a LinearMixture Packing Model”, Ind. Eng. Chem., Vol. 30, pp. 1372 - 1386, 1991. 
20. J. P. Holman, Heat Transfer, $4^{\text {th }}$ edition, McGraw-Hill Book Company, New York (1976).

21. R. H. Perry and C. H. Chilton, Chemical Engineers' Handbook, McGraw-Hill Book Company, New York (1973).

22. R. G. Baxter, "Defense Waste Processing Facility Wasteform and Canister Description", Dupont Company document, DP-1606, Rev. 2 (1988).

23. S. Y. Lee, R. A. Dimenna, R. A. Leishear, D. B. Stefanko, 2008, "Analysis of Turbulent Mixing Jets in a Large Scale Tank", ASME Journal of Fluids Engineering, vol. 130, Number 1, pp. 011104, 2008.

24. W. E. Jones, M. R. Millings, and B. H. Rambo, "Hydrogeologic Data Summary In Support Of The H-Area Tank Farm Performance Assessment", SRNL-STI-201000148, rev. 0, February 2010. 